\title{
Mixing-Driven Mean Flows and Submesoscale Eddies over Mid-Ocean Ridge Flanks and Fracture Zone Canyons
}

\author{
XIAOZHOU RUAN ${ }^{\mathrm{a}}$ AND JÖRN CALLIES \\ California Institute of Technology, Pasadena, California
}

(Manuscript received 30 July 2019, in final form 24 October 2019)

\begin{abstract}
To close the abyssal overturning circulation, dense bottom water has to become lighter by mixing with lighter water above. This diapycnal mixing is strongly enhanced over rough topography in abyssal mixing layers, which span the bottom few hundred meters of the water column. In particular, mixing rates are enhanced over mid-ocean ridge systems, which extend for thousands of kilometers in the global ocean and are thought to be key contributors to the required abyssal water mass transformation. To examine how stratification and thus diabatic transformation is maintained in such abyssal mixing layers, this study explores the circulation driven by bottom-intensified mixing over mid-ocean ridge flanks and within ridge-flank canyons. Idealized numerical experiments show that stratification over the ridge flanks is maintained by submesoscale baroclinic eddies and that stratification within ridge-flank canyons is maintained by mixing-driven mean flows. These restratification processes affect how strong a diabatic buoyancy flux into the abyss can be maintained, and they are essential for maintaining the dipole in water mass transformation that has emerged as the hallmark of a diabatic circulation driven by bottom-intensified mixing.
\end{abstract}

\section{Introduction}

The abyssal ocean stores and exchanges vast amounts of carbon and heat with the atmosphere and is thought to regulate Earth's climate on centennial to millennial time scales (Sarmiento and Toggweiler 1984; Primeau and Holzer 2006). In the present abyssal circulation, bottom waters form around Antarctica, sink to the ocean bottom, and spread into all ocean basins (Lumpkin and Speer 2007; Talley 2013). The high-latitude sinking must be balanced by upwelling across isopycnals, which is enabled by small-scale turbulence that mixes the dense bottom water with the lighter water above (e.g., Munk 1966; Ferrari 2014; MacKinnon et al. 2017).

Over the past 25 years, it has become increasingly clear that the intensity of the small-scale turbulence that allows flow across isopycnals is highly nonuniform in space, implying that the pathways of Antarctic Bottom Water (AABW) back toward the surface are much more complicated than the uniform upwelling originally

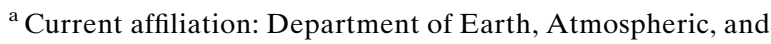
Planetary Sciences, Massachusetts Institute of Technology, Cambridge, Massachusetts.
}

Corresponding author: Xiaozhou Ruan, xruan@mit.edu envisioned by Stommel and Arons (1959). Where tidal and subinertial flows pass over a rough sea floor, turbulence is strongly enhanced in abyssal mixing layers that span the bottom few hundred meters of the water column (Polzin et al. 1997; Ledwell et al. 2000; Waterhouse et al. 2014). Given the observed stratification, this bottom intensification of mixing implies a dipole of diapycnal velocities. Downwelling occurs where turbulent buoyancy fluxes increase toward the bottom and thus diverge; upwelling occurs where buoyancy fluxes converge, typically within tens of meters of the sea floor. This suggests that the net diapycnal upwelling of $\mathrm{AABW}$ is a residual of larger but compensating transports across isopycnals (Ferrari et al. 2016; de Lavergne et al. 2016; Holmes et al. 2018). The up- and downwelling dipole on the slopes of large-scale topographic features has been argued to shape the horizontal circulation of the abyssal ocean (Callies and Ferrari 2018b) and the transport of tracers in abyssal mixing layers (Holmes et al. 2019).

For small-scale turbulence to support a diapycnal circulation, it must occur in stratified water (Garrett 1979, 1990). Bottom-intensified mixing on a large-scale slope quickly erodes the stratification in abyssal mixing layers if left unopposed (Thompson and Johnson 1996; Callies 2018). The mean flows up and down the slope 

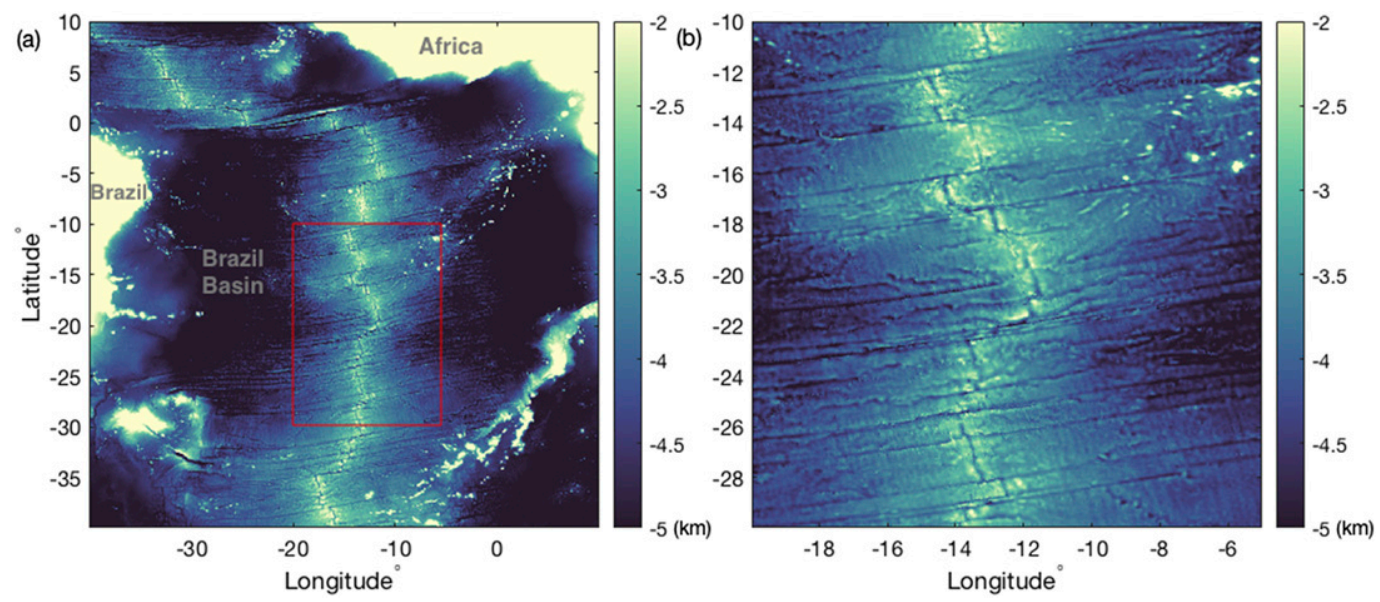

FIG. 1. The Mid-Atlantic Ridge bathymetry and ridge flank canyons. (a) Bathymetry in the South Atlantic from the Smith and Sandwell dataset (Smith and Sandwell 1997; version 18.1). (b) Zoom-in to the red rectangle, showing the fracture zone canyon bathymetry on the ridge flanks. Note that this dataset resolves abyssal hills only in a few locations, where multibeam data are available.

that develop in response to the mixing are too weak to maintain realistic stratification. But the mixing generates potential energy and powers submesoscale baroclinic eddies, whose buoyancy fluxes restratify abyssal mixing layers (Wenegrat et al. 2018; Callies 2018). A realistically strong stratification, as compared with observations, can be maintained by a balance between the homogenizing effect of the mixing and the restratifying effect of submesoscale eddies. This restratification is achieved through an adiabatic rearrangement similar to that by mesoscale eddies in the thermocline (e.g., Gent et al. 1995) or by submesoscale eddies in the surface mixed layer (e.g., Fox-Kemper et al. 2008; Callies and Ferrari 2018a).

Using idealized numerical simulations, we here study the circulation driven by bottom-intensified mixing in geometries that are more realistic than those considered previously, and we explore whether stratification can be maintained by other mechanisms than submesoscale eddies. The calculations presented in Callies (2018) considered the dynamics over a uniform slope, in a setup pioneered by Phillips (1970) and Wunsch (1970) in their study of boundary layers of a rotating stratified fluid adjacent to a sloping boundary. That setup precluded any effects arising from changes in the topographic slope on both large and small scales.

The geometries we consider in this study are meant to idealize a mid-ocean ridge like the Mid-Atlantic Ridge in the South Atlantic (Fig. 1). The western flank of the Mid-Atlantic Ridge bounds the Brazil basin, whose abyssal mixing and circulation has been studied with extensive observational programs (e.g., Hogg et al. 1982; Polzin et al. 1997; Hogg and Owens 1999; Ledwell et al.
2000; Thurnherr et al. 2005; Clément et al. 2017). In the Brazil basin, an estimated 4 Sverdrups (Sv; $1 \mathrm{~Sv} \equiv$ $10^{6} \mathrm{~m}^{3} \mathrm{~s}^{-1}$ ) of AABW are consumed diabatically (Hogg et al. 1982). Microstructure surveys have revealed that the mixing is weak on the sedimented abyssal plains and continental slopes in the west and is elevated and bottom intensified over the rough ridge flank in the east (Polzin et al. 1997). This strong mixing on the ridge flank is generally thought to be produced by breaking internal waves that are generated by tidal flows over abyssal hill topography (Polzin et al. 1997; Ledwell et al. 2000; Nikurashin and Legg 2011), although nearinertial waves and mean flows may contribute as well (Thurnherr et al. 2005; Toole 2007; Clément et al. 2017). Abyssal hills are of order $1-10 \mathrm{~km}$ in scale and elongated in the direction of the ridge axis.

We here idealize the Mid-Atlantic Ridge geometry into a sinusoidal large-scale ridge (Fig. 2a). We study the subinertial response to prescribed bottom-intensified mixing everywhere over this ridge. We do not explicitly represent the abyssal hills that are responsible for producing the mixing, because computational constraints prevent us from resolving the generation and breaking of internal waves while considering the entire mid-ocean ridge spanning thousands of kilometers. We instead specify a bottom-intensified profile of diffusivity that is consistent with microstructure profiles from the Mid-Atlantic Ridge flank (Polzin et al. 1997; St. Laurent et al. 2001). We neglect spatial variations of mixing, that is, we focus on the ridge flanks with intense mixing rather than the abyssal plains and continental slopes with weak mixing. We specify strong bottomintensified mixing everywhere. 

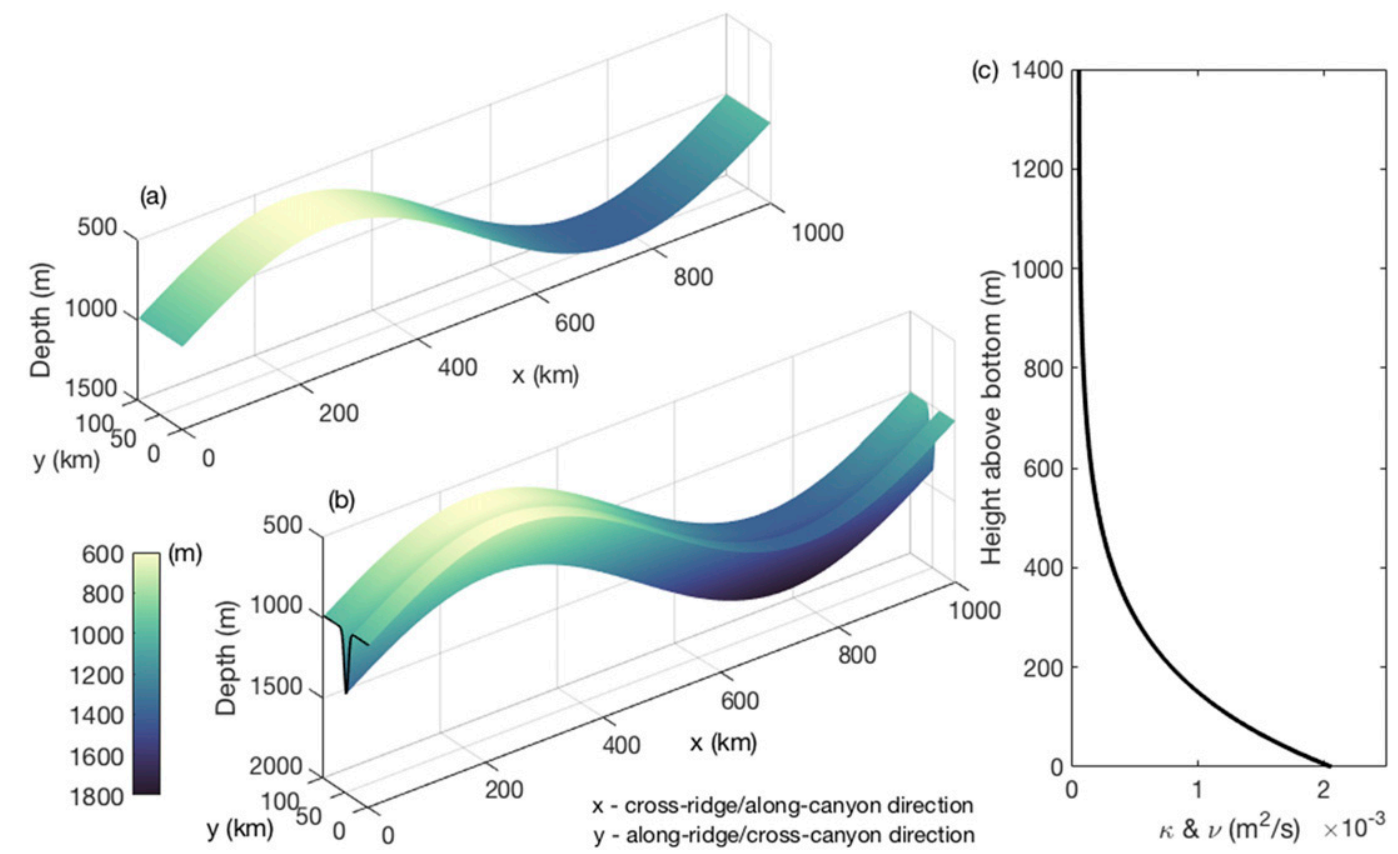

FIG. 2. Topography and diffusivity/viscosity profiles used in the model simulations. (a) Model topography for the three-dimensional simulation without a canyon. (b) Model topography for the three-dimensional simulation with a canyon. (c) Diffusivity and viscosity profile as a function of height above the bottom.

In contrast to a uniform slope, the full ridge considered here has cross-ridge variations in the slope and thus allows for cross-ridge variations in the mixing-driven flow. Such variations can drive mass convergence or divergence and thus a so-called tertiary circulation (e.g., Garrett 1991; Dell and Pratt 2015; Holmes et al. 2018). It is so far unclear whether this affects the mixing-layer stratification and its maintenance in the face of bottomintensified mixing, which will be the first topic investigated in this study. The simulations presented below indicate that cross-slope mean flows in the ridge system are even weaker than on a uniform slope, rendering mean flow restratification of abyssal mixing layers even weaker (section 3a). Like on a uniform slope (Callies 2018), submesoscale eddies emerge and maintain stratification (section 3b).

Moreover, mid-ocean ridge flanks are typically interrupted by deep fracture zone canyons (Fig. 1). Mooring observations have revealed an up-ridge mean flow that is greater than $0.01 \mathrm{~m} \mathrm{~s}^{-1}$ in a particularly deep canyon (Thurnherr et al. 2005). This observed up-ridge mean flow is much stronger than predicted by one-dimensional theory on a uniform slope (Callies 2018). The second topic of this study is thus to examine how fracture zone canyons affect the equilibration of bottom-intensified mixing. Can up-ridge mean flows within canyons be strong enough to maintain stratification without the need for restratification by submesoscale eddies? In calculations with uniform mixing and an infinitely deep rectangular canyon, Dell (2013) found mean flows parallel to the canyon axis that were indeed stronger than predicted by one-dimensional theory, but these flows were oriented largely along isopycnals and thus had little effect on the stratification. We here extend Dell's calculations to the more realistic case with bottomintensified mixing and a canyon that has sloping walls and is embedded in a ridge flank (Fig. 2b). We find that mean flows in canyons can indeed maintain stratification there, but cross-canyon flows up and down the sloping canyon walls appear to play a key role. On the ridge flanks away from the canyons, submesoscale eddies remain important (section 4).

Finally, we discuss how the flow and restratification mechanisms affect integrated buoyancy fluxes and water mass transformation rates (section 5). We find that submesoscale eddies and fracture zone canyons both enhance buoyancy fluxes into the abyss and cause modestly higher water mass transformation rates.

\section{Numerical model configuration}

All numerical experiments described below employ the same basic model configuration. We use the Massachusetts Institute of Technology general circulation model (MITgcm; Marshall et al. 1997) to solve the hydrostatic Boussinesq equations: 


$$
\begin{aligned}
u_{t}+\mathbf{u} \cdot \nabla u-f v & =-p_{x}+\left(\nu u_{z}\right)_{z}-\nu_{4} \nabla_{h}^{4} u, \\
v_{t}+\mathbf{u} \cdot \nabla v+f u & =-p_{y}+\left(\nu v_{z}\right)_{z}-\nu_{4} \nabla_{h}^{4} v, \\
b & =p_{z}, \\
\nabla \cdot \mathbf{u} & =0, \quad \text { and } \\
b_{t}+\mathbf{u} \cdot \nabla b+w N^{2} & =\left[\kappa\left(N^{2}+b_{z}\right)\right]_{z}-\kappa_{4} \nabla_{h}^{4} b .
\end{aligned}
$$

Here, $\mathbf{u}=u \mathbf{x}+v \mathbf{y}+w \mathbf{z}$ is the velocity vector, the buoyancy anomaly $b$ is defined as a perturbation from the background buoyancy profile $N^{2} z$, and $p$ is the pressure anomaly normalized by a constant reference density. The subscripts $t, x, y$, and $z$ denote differentiation. Biharmonic horizontal diffusion with coefficients $\nu_{4}=\kappa_{4}=3 \times 10^{4} \mathrm{~m}^{4} \mathrm{~s}^{-1}$ is included to absorb gridscale fluctuations. In the $x$ direction, the model domain is $L_{x}=1000 \mathrm{~km}$ wide, and the grid spacing is $\Delta x=0.8 \mathrm{~km}$. In the $y$ direction, if present, the domain is $L_{y}=100 \mathrm{~km}$ wide, and the grid spacing is $\Delta y=0.8 \mathrm{~km}$ as well. The vertical grid spacing is $\Delta z=2 \mathrm{~m}$. The model is integrated with a time step of $320 \mathrm{~s}$. The vertical diffusivity $\kappa$ and viscosity $\nu$ are prescribed as profiles depending on the local height above the bottom, which is located at $z=-H(x, y)$ :

$$
\nu=\kappa=\kappa_{0}+\kappa_{1} e^{-(z+H) / h} .
$$

The values $\kappa_{0}=6 \times 10^{-5} \mathrm{~m}^{2} \mathrm{~s}^{-1}, \kappa_{1}=2 \times 10^{-3} \mathrm{~m}^{2} \mathrm{~s}^{-1}$, and $h=200 \mathrm{~m}$ are similar to those obtained by fitting this functional form to the observed bottom-enhanced diffusivity profile observed in the Brazil basin (Fig. 2c; Polzin et al. 1997; Callies 2018). The turbulent Prandtl number is set to $\operatorname{Pr}=\nu / \kappa=1$. All these values are fixed throughout the numerical experiments, along with the inertial frequency $f=-5.5 \times 10^{-5} \mathrm{~s}^{-1}$ for a central latitude of the Brazil basin. The background buoyancy frequency is $N=10^{-3} \mathrm{~s}^{-1}$. Insulating boundary conditions are applied at both the bottom and the top of the model domain. No-slip and free-slip conditions are used at the bottom and top, respectively. Periodic boundary conditions are imposed in both horizontal directions.

Our model simulations all start from rest and a uniform background stratification, that is, $u=v=b=0$. The flow emerges in response to the bottom-intensified mixing, which tilts isopycnals and thus produces pressure gradient forces. The generation of potential energy by the mixing is the only energy source of the system. In all simulations, we add small random perturbations to the initial buoyancy field (drawn from a normal distribution with standard deviation $10^{-5} \mathrm{~m} \mathrm{~s}^{-2}$ ) to break the along-ridge symmetry (if present).
All our model solutions are transient. The long-term equilibrium they would eventually reach is an unrealistic homogeneous ocean with no flow because there is no inflow of bottom water or outflow of upwelled water in our setup. Our transient simulations can shed light on the mixing-layer dynamics, however, because these dynamics equilibrate much more rapidly than the time needed to homogenize the entire water column. Quasiequilibrated mixing-layer dynamics thus emerge on top of a slowly drifting background state.

\section{Mean flows and submesoscale eddies over mid-ocean ridge flanks}

Boundary layer theory describes how a stratified and rotating fluid adjacent to a sloping boundary responds to small-scale mixing (Phillips 1970; Wunsch 1970; Thorpe 1987; Garrett et al. 1993). Boundary layer solutions describe the near-bottom tilting of isopycnals by the mixing and the along- and cross-slope flows that develop in response. These solutions are one-dimensional, that is, they depend on the slope-normal direction only. All variations in the plane of the slope are neglected.

The dynamics in a coordinate system aligned with the slope are (e.g., Garrett et al. 1993)

$$
\begin{aligned}
\dot{u}_{t}-f \dot{v} \cos \theta & =b \sin \theta+\left(\nu \dot{u}_{\dot{z}}\right)_{\dot{z}}, \\
\dot{v}_{t}+f \dot{u} \cos \theta & =\left(\nu \dot{v}_{\dot{z}}\right)_{\dot{z}}, \quad \text { and } \\
b_{t}+\dot{u} N^{2} \sin \theta & =\left[\kappa\left(N^{2} \cos \theta+b_{\dot{z}}\right)\right]_{\dot{z}},
\end{aligned}
$$

where $z$ is the slope-normal coordinate, $u$ is the crossslope flow, $v$ is the along-slope flow, and $\theta$ is the angle between the uniform slope and the horizontal. The diffusive buoyancy flux in the slope-normal direction is $F_{b}^{\dot{z}}=-\kappa\left(N^{2} \cos \theta+b_{\dot{z}}\right)$.

Solutions to these one-dimensional equations capture the physics of how mixing on slopes can be equilibrated by mean flows. With a bottom-intensified diffusivity, buoyancy flux divergence $\left(-\partial F_{b}^{z} / \partial \dot{z}<0\right)$ in an outer layer with a thickness of order $1000 \mathrm{~m}$ is balanced by downslope flow that advects light water from above, and buoyancy flux convergence $\left(-\partial F_{b}^{z} / \partial \dot{z}>0\right)$ in an inner layer with a thickness of order $10 \mathrm{~m}$ is balanced by up-slope flow that advects dense water from below (Garrett 1990, 1991; Callies 2018). Isopycnals tilt over the entire outer layer, and the associated lateral buoyancy gradient is in thermal wind balance with the along-slope flow, which is much stronger than the cross-slope flow.

The one-dimensional solutions thus qualitatively capture the expected up- and downwelling dipole inferred from observations. But the stratification predicted by 
these solutions is much weaker than what is observed (Callies 2018). If the homogenizing tendency of bottomintensified mixing was opposed only by the cross-slope mean flows predicted by one-dimensional theory, the stratification in abyssal mixing layers would quickly erode.

As discussed in Wenegrat et al. (2018) and Callies (2018), this mismatch should not come as a surprise because the steady one-dimensional solution is unstable to submesoscale baroclinic instability. Submesoscale eddies develop in response to this instability and restratify the mixing layer. The observed stratification can arise as an equilibrium between the homogenizing tendency of the mixing and the restratifying tendency of submesoscale eddies.

In this section, we substantiate the proposal that submesoscale eddies are required by ruling out that large-scale slope variations can produce a better match with observations without the need to appeal to submesoscale dynamics. Boundary layer theory neglects any variations of the flow in the plane of the slope. Such variations can arise if the far-field stratification is not constant (e.g., Phillips et al. 1986), if the mixing is inhomogeneous in the plane of the slope (e.g., McDougall 1989), and if there are variations in the slope itself (e.g., Dell and Pratt 2015; Holmes et al. 2018). We here focus on the latter case, considering a full mid-ocean ridge (Fig. 2a) and comparing the dynamics on the ridge flanks to those emerging on uniform slopes. We show that in two-dimensional dynamics, which capture the slope variations yet still disallow baroclinic instability, crossslope mean flows are even weaker and mixing-layer stratification is eroded even more rapidly than in the one-dimensional case (section 3a). In three-dimensional dynamics, mixing-layer stratification is again restored by submesoscale baroclinic eddies (section 3b). The conclusion of this section is thus that submesoscale eddies appear crucial for maintaining mixing-layer stratification, not only on uniform slopes but also on the flanks of an idealized mid-ocean ridge.

\section{a. The two-dimensional simulation}

We consider a ridge of sinusoidal shape, a wavelength of $1000 \mathrm{~km}$, an amplitude of $400 \mathrm{~m}$, and a mean depth of $1000 \mathrm{~m}$ (Fig. 2a). Our ridge is narrower and less tall than the Mid-Atlantic Ridge, which saves us computational cost yet keeps the slopes of the ridge flanks in a realistic range. We expect the smaller size of the ridge to have no qualitative effect on the dynamics. The setup is as described in section 2, except that no $y$ dependence is allowed in this two-dimensional case. Given that the system is rotating, there is of course still flow in the unresolved along-ridge direction. In this section, we use "cross-ridge" and "cross-slope" interchangeably to refer to the $x$ direction; "along-ridge" and "along-slope" refer to the $y$ direction.

As the initially flat isopycnals are tilted down into the ridge flanks by the prescribed mixing, buoyancy forces accelerate the water in the cross-ridge direction. In a thin inner layer near the bottom, an up-ridge flow of order $10^{-4} \mathrm{~m} \mathrm{~s}^{-1}$ develops (Fig. 3a). A weaker downwelling emerges in a broader outer layer above (Fig. 3a). Because of Earth's rotation, an along-ridge flow of order $0.01 \mathrm{~m} \mathrm{~s}^{-1}$ develops (Fig. 3b). Its shear is in thermal wind balance in the downwelling layer, and it is nearly depth independent above. The mixing-layer stratification is strongly reduced after a few hundred days-isopycnals are practically vertical (Fig. 3).

The flow and stratification on the ridge flanks produced by two-dimensional dynamics thus qualitatively match those predicted by one-dimensional dynamics. To compare the dynamics more quantitatively, we obtain a transient one-dimensional solution for the slope at the center of the ridge flank $(x=0)$, where $\theta=2.5 \times 10^{-3}$. We use Dedalus (Burns et al. 2019) to integrate these equations, projecting the slope-normal direction onto 256 Chebyshev modes. The domain height is $2500 \mathrm{~m}$, which is tall enough not to affect the solution in the mixing layer. Time stepping is performed with an implicit third-order Runge-Kutta scheme and a time step of $3 \mathrm{~h}$.

Quantitative differences emerge between the flows in the one- and two-dimensional systems (Figs. 4a-d). The cross-slope flow in the inner layer is nearly 10 times greater in the one-dimensional solution than the twodimensional solution, whereas the downslope flow in the outer layer is comparable. The along-slope flow has similar shear in the two solutions, but the flow magnitude is of order $0.01 \mathrm{~m} \mathrm{~s}^{-1}$ at the outer edge of the inner layer (around $z=20 \mathrm{~m}$ ) in the one-dimensional solution, whereas it is close to zero at the same height in the twodimensional solution. In the two-dimensional solution, the along-ridge flow equilibrates more quickly in the outer layer and changes more rapidly in the far field, that is, outside of the abyssal mixing layer. We offer an explanation for these differences below.

Since the cross-ridge flow is weaker in the twodimensional system than in the one-dimensional uniformslope case (Figs. 4a,b), the cross-slope buoyancy advection and thus the associated mean flow restratification are also weaker. As a result, mixing erodes the stratification in the mixing layer even more rapidly than in the one-dimensional case (Figs. 4e,f and 5a,b). Like in the one-dimensional case, stratification becomes unrealistically weak throughout the outer layer, indicating that the two-dimensional setup also does not capture 


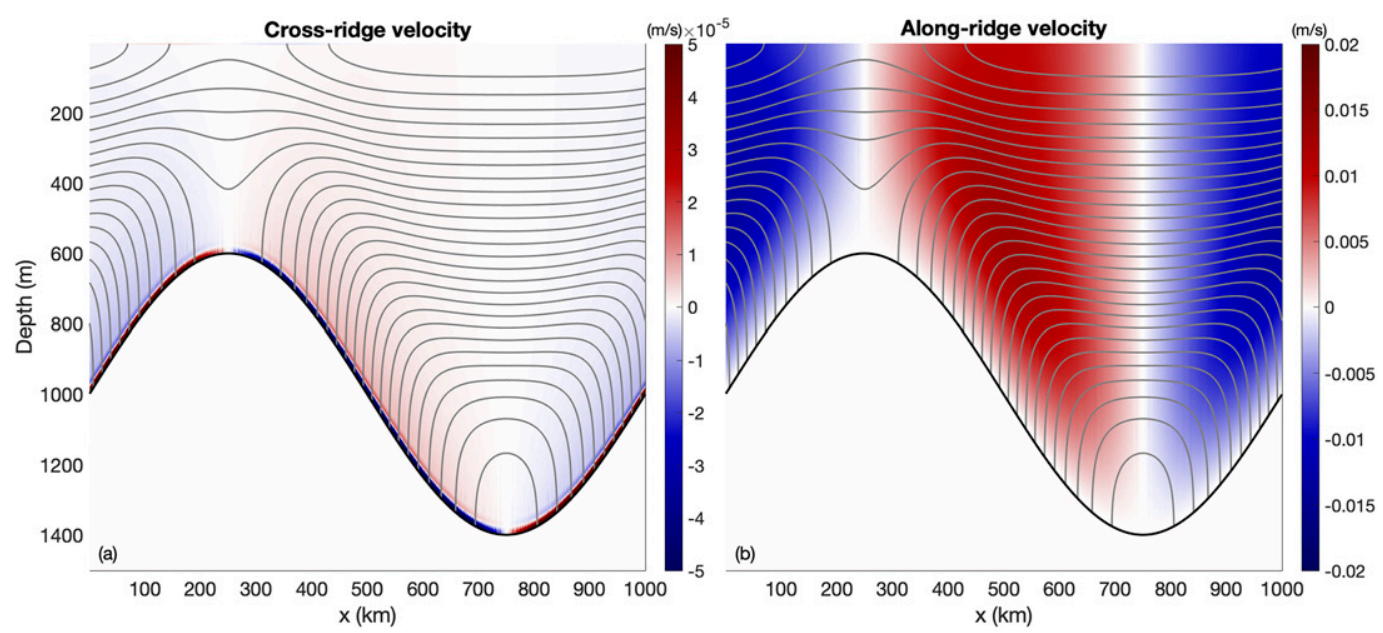

FIG. 3. Flow in the two-dimensional simulation at day 1000. (a) Cross-ridge flow showing strong bottom-trapped upwelling and a weaker return flow in the mixing layer above. (b) Along-ridge flow showing thermal wind shear in the weakly stratified layer and nearly depth-independent flow above. The gray contours show isopycnals. The crossridge velocity structure near the bottom can be seen more clearly in Fig. $4 \mathrm{~b}$.

the physics required to maintain realistic mixing-layer stratification. ${ }^{1}$

The weak cross-ridge inner-layer flow in the twodimensional solution goes hand in hand with a weak along-ridge flow at the outer edge of the inner layer (Figs. 4b,d). For the small slope Burger numbers typical of the abyssal ocean (here the slope Burger number is $\left.S=N^{2} \tan ^{2} \theta / f^{2}=2 \times 10^{-3}\right)$, the flow in the inner layer follows Ekman layer dynamics (Wunsch 1970; Garrett et al. 1993; Callies 2018). The cross-ridge flow in the inner layer is thus part of the Ekman adjustment of the along-ridge flow to the no-slip boundary condition. To understand why the cross-ridge flow is weaker in the two-dimensional solution than in the one-dimensional solution, we must therefore understand why the along-ridge flow at the outer edge of the inner layer is weaker.

The tilting of isopycnals in the outer layer is similar between the one- and two-dimensional solutions and thus produces similar thermal-wind shear there. This along-slope shear is southward on the western flank of the ridge and northward on the eastern flank. A state with small near-bottom along-slope flow thus requires a far-field along-ridge flow that is southward on the western flank and northward on the eastern flank. The two-dimensional solution produces such far-field flow

\footnotetext{
${ }^{1}$ The discrepancies in the stratification near the top boundary of the two-dimensional domain are due to the insulating boundary condition there, which is not present in the one-dimensional solution. At the times considered here, the one-dimensional solution behaves as if the domain was semi-infinite.
}

(Figs. 3b and 4d) - the one-dimensional solution does not (Fig. 4c).

The difference in the along-slope flow between the one-dimensional and two-dimensional solutions arises because the up-slope Ekman transport must be returned in the two-dimensional system, whereas no such constraint exists in the one-dimensional system. In the twodimensional system, continuity and the symmetry of the geometry imply that

$$
\int_{-H}^{0} u d z=0 \text { for all } x \text { and } t .
$$

Any up-slope Ekman transport must thus be returned above. That return flow produces a Coriolis force that accelerates the along-slope flow in a way that reduces the near-bottom along-slope flow. There is thus a negative feedback on the strength of the near-bottom alongslope flow and associated up-slope Ekman transport. As a result, the far-field along-slope flow adjusts such that the thermal-wind shear produces near-zero flow at the outer edge of the inner layer (Fig. 4d). This negative feedback is absent in the one-dimensional system.

More formally, the vertical integral of the along-ridge momentum equation (8) of the one-dimensional system yields

$$
\frac{\partial}{\partial t} \int_{0}^{\infty} \dot{v} d \dot{z}=-f \cos \theta \int_{0}^{\infty} \dot{u} d \dot{z}-\left.\nu \dot{v}_{\dot{z}}\right|_{\dot{z}=0},
$$

where the bottom is at $\dot{z}=0$. Except for a short initial adjustment, the dominant balance is between the two terms on the right: the bottom stress balances the Coriolis force on the integrated up-slope transport 

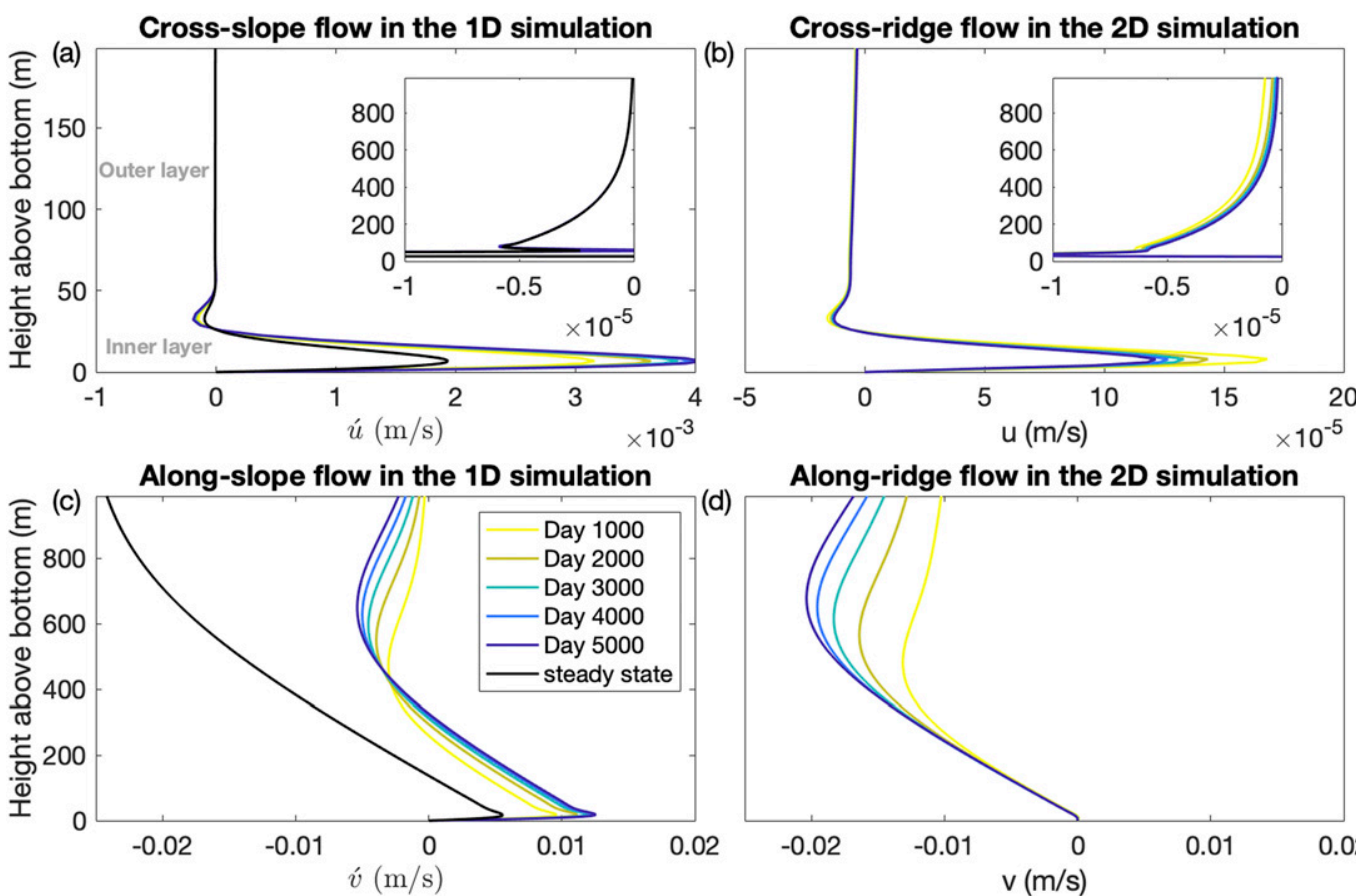

(d)

Along-ridge flow in the 2D simulation
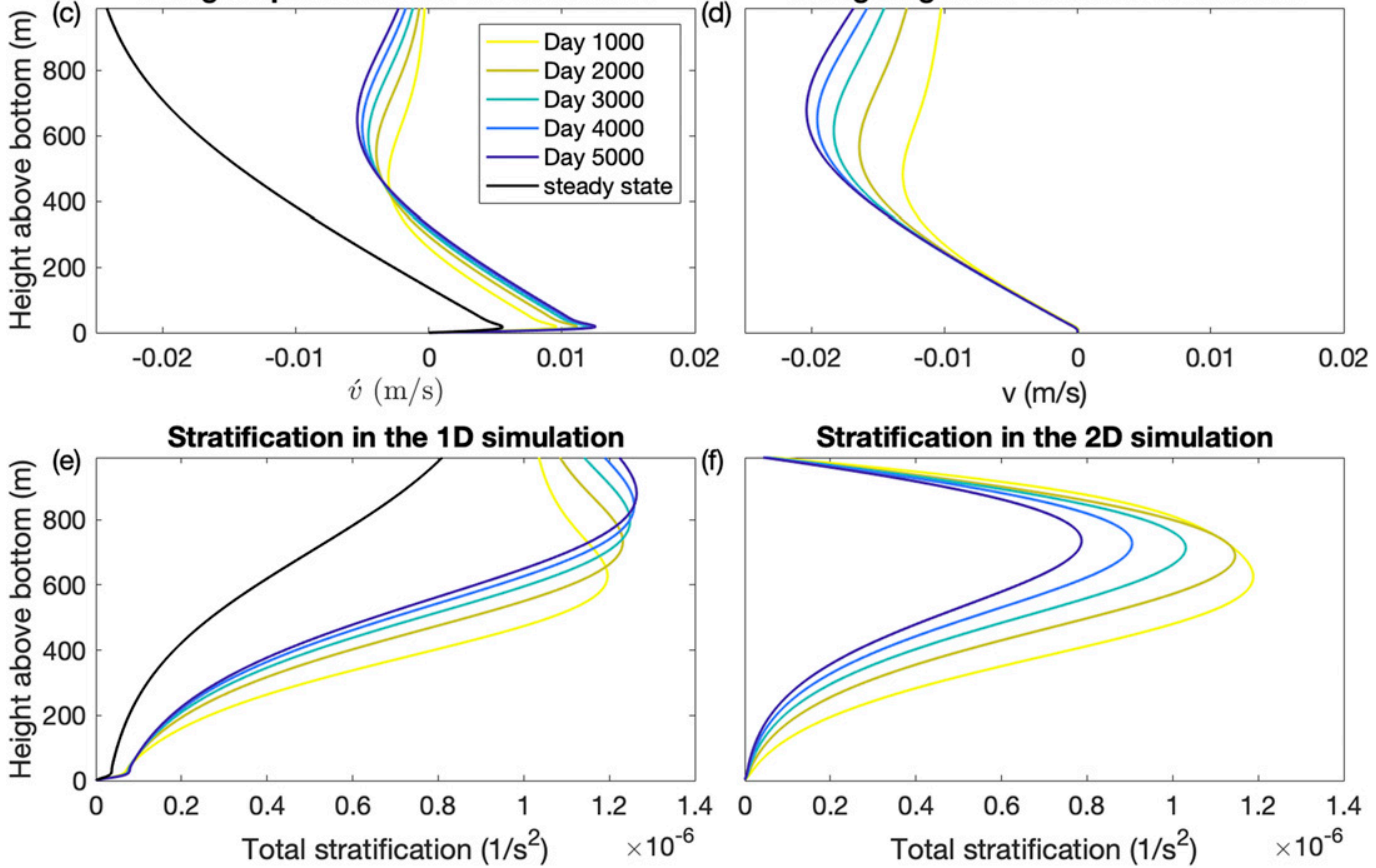

FIG. 4. Comparison between (left) the transient one-dimensional uniform-slope solution and (right) the two-dimensional model solution at the center of the ridge flank $(x=0)$. (a),(b) Cross-slope velocity profiles $u$ and $u$ (the velocity structures extending to $1000 \mathrm{~m}$ are shown in the insets), (c),(d) along-slope velocity profiles $v$ and $v$, and (e),(f) stratification profiles $N^{2} \cos \theta+b_{z}$ and $N^{2}+b_{z}$. The times after initialization are noted in the legend. For the one-dimensional solution, we also show the steady state (black lines). Note that we ignore the small slope angle between the horizontal and cross-slope direction in the two-dimensional model solution. Also note the difference in the velocity axis between (a) and (b).

(cf. Fig. 4c). In contrast, the balance in the twodimensional system is

$$
\frac{\partial}{\partial t} \int_{-H}^{0} v d z=-\left.\nu v_{z}\right|_{z=-H},
$$

because the integrated cross-ridge transport vanishes. The only way for the two-dimensional system to produce a slow drift in the along-ridge flow is to adjust to a state with reduced bottom stress (cf. Fig. 4d).

\section{$b$. The three-dimensional simulation}

We now allow for flow variations in the along-ridge direction $y$, but we retain a smooth ridge flank (Fig. 2a).
Like in the uniform-slope case discussed in Callies (2018), we expect submesoscale baroclinic eddies to develop, laterally slide dense water under light water, and maintain stratification in abyssal mixing layers.

In the same transient experiment started from a state of rest and a uniform stratification, we again see isopycnals tilt down into the slope, producing available potential energy. Once potential energy has built up, initially small perturbations grow into baroclinically unstable modes and subsequently into finite-amplitude submesoscale baroclinic eddies. The eddies have a typical size of $10 \mathrm{~km}$ and are strongest in the mixing layers over the ridge flanks (Fig. 6a). We characterize these 

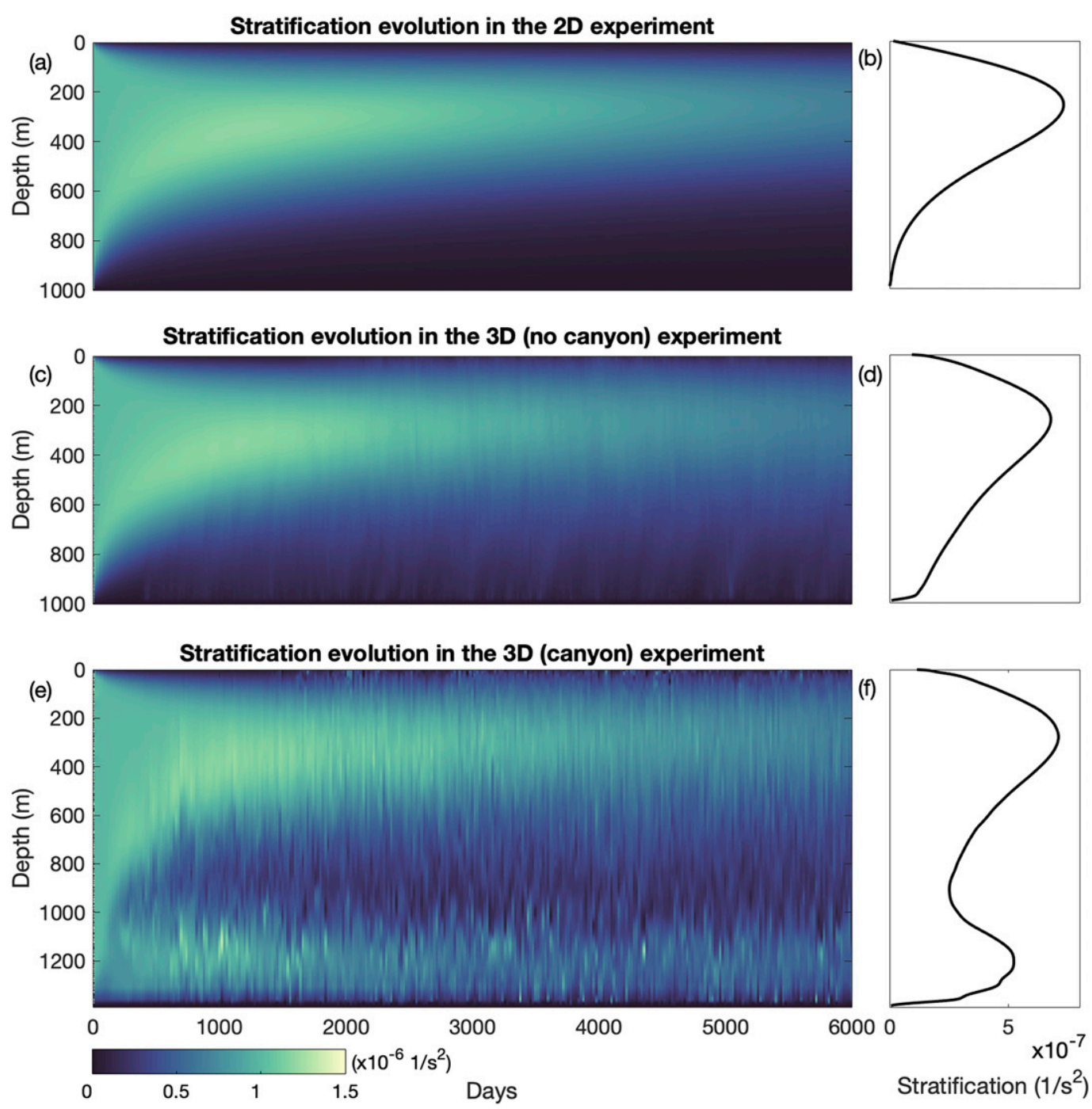

FIG. 5. Submesoscale eddies maintain stratification over the ridge flanks, canyon flows maintain stratification in the canyon. The evolution of stratification at the center of the ridge flank $(x=0)$ is shown for (a) the twodimensional simulation, (c) the three-dimensional simulation without a canyon, averaged over the along-ridge direction, and (e) the three-dimensional simulation with a canyon in the center of the canyon $(y=50 \mathrm{~km}$, not averaged). (b),(d),(f) The stratification profiles averaged over the last 1000 days.

eddies as "submesoscale" to emphasize their small spatial scale relative to mesoscale thermocline eddies, without necessarily implying strongly ageostrophic dynamics.

As a result of the buoyancy fluxes achieved by these eddies, the mixing layers remain more stratified than in the two-dimensional case (Figs. $5 \mathrm{c}, \mathrm{d}$ and $7 \mathrm{a}, \mathrm{d}$ ). The sharp difference in the stratification emerges after day 200 , when the baroclinic eddies first reach appreciable amplitude. The restratification is less strong over the ridge crest, where the lateral buoyancy gradients are weaker (Fig. 7d).

We thus confirm that submesoscale baroclinic eddies play an important role in maintaining the stratification over the flanks of a smooth threedimensional mid-ocean ridge. The phenomenology on the ridge flanks is consistent with the vigorous restratification by submesoscale eddies found on uniform slopes (Callies 2018).

\section{Circulation and restratification in ridge flank canyons}

We now turn to discussing how the presence of a fracture zone canyon modifies the flow and stratification on mid-ocean ridge flanks. We find that-in contrast to the smooth ridge flanks in the previous case-strong 

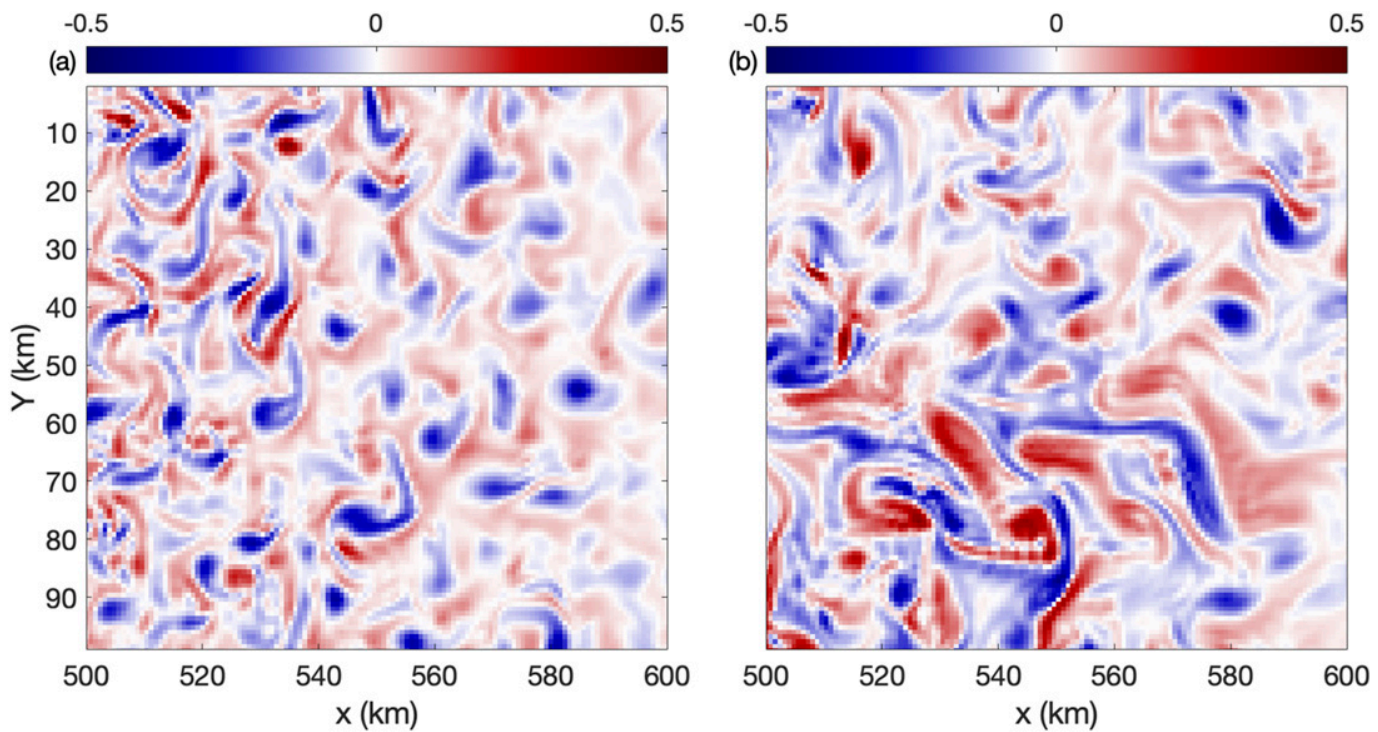

FIG. 6. Submesoscale baroclinic eddies over the mid-ocean ridge flank in the three-dimensional simulations. Shown is the vertical component of relative vorticity $\zeta=v_{x}-u_{y}$, normalized by the inertial frequency $f$, at $z=800 \mathrm{~m}$ on day 1000 for (a) the simulation without a canyon and (b) the simulation with a canyon.

mean flows emerge within the canyon and maintain stratification there.

We add to our large-scale ridge bathymetry a fracture zone canyon that runs across the flanks of the ridge (Fig. 2b). We insert at $y=50 \mathrm{~km}$ one deep canyon oriented along the $x$ direction. As the domain is periodic and $100 \mathrm{~km}$ wide in the along-ridge direction, the setup can be thought of as having a canyon running across the ridge flank every $100 \mathrm{~km}$. The canyon has the shape of a Gaussian and is $400 \mathrm{~m}$ deep and about $20 \mathrm{~km}$ wide:
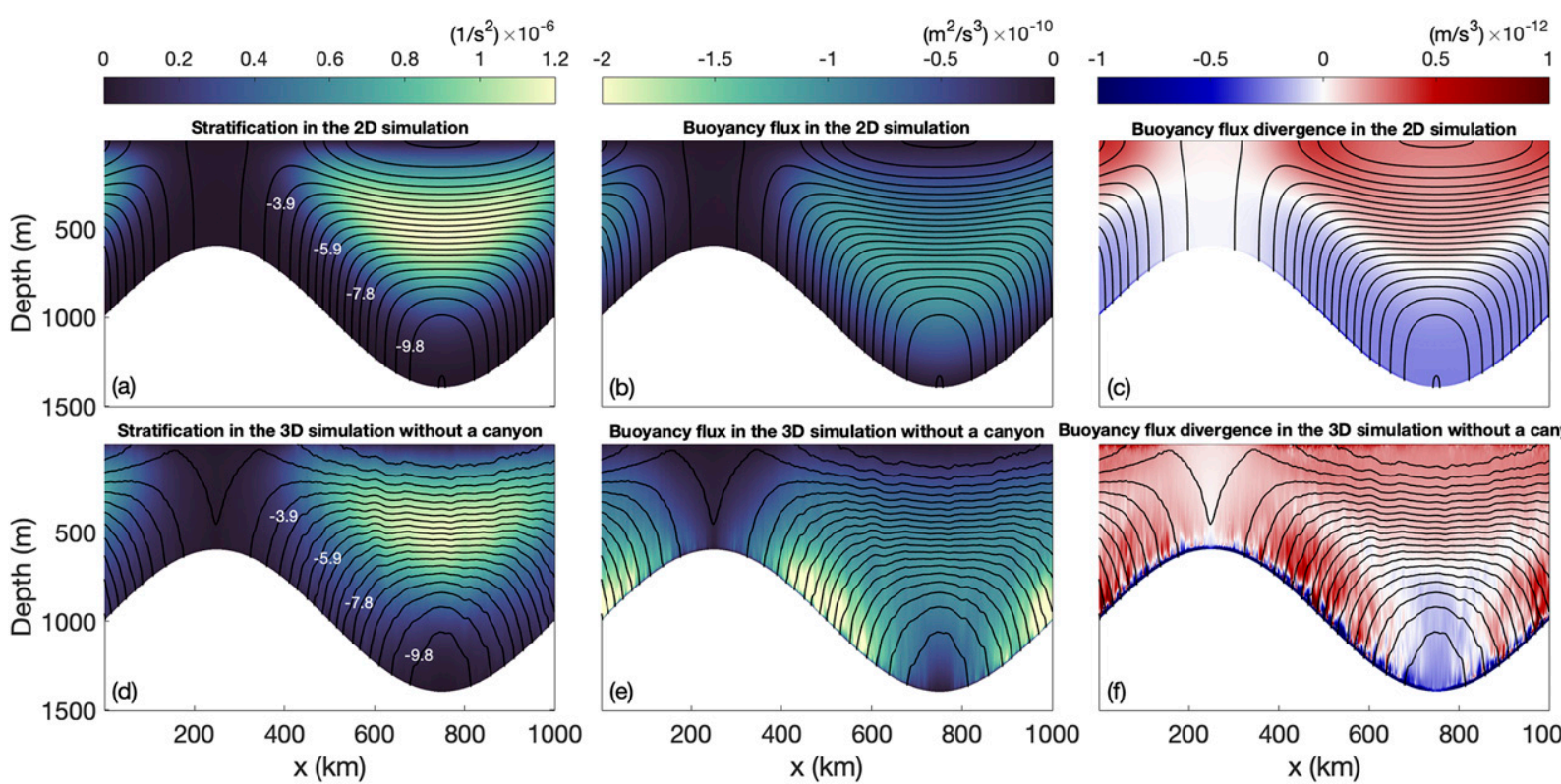

(c)

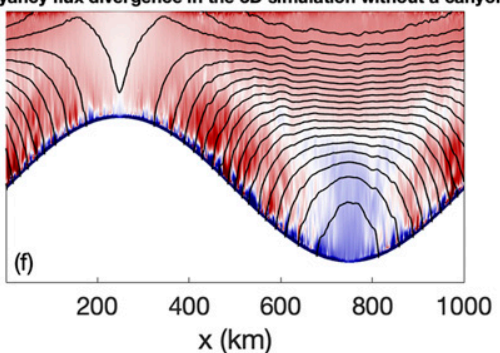

FIG. 7. Comparison between the two-dimensional and three-dimensional simulations without a canyon. (a) Stratification in the two-dimensional simulation, (b) resulting vertical buoyancy flux $F_{b}^{z}=\mathbf{F}_{b} \cdot \mathbf{z}=-\kappa\left(N^{2}+b_{z}\right)$, and (c) its divergence $\partial F_{b}^{z} / \partial z$; (d) stratification in the three-dimensional simulation, (e) resulting vertical buoyancy flux, and (f) its divergence. All fields are shown for day 6000. The three-dimensional fields are averaged over the along-ridge dimension. The black contours are isopycnals. Four buoyancy levels are labeled in (a) and (d) (given in $10^{-4} \mathrm{~m} \mathrm{~s}^{-2}$ ). 


$$
H_{c}(y)=H_{0} \exp \left[-\frac{\left(y-y_{0}\right)^{2}}{2 \sigma^{2}}\right],
$$

with $H_{0}=400 \mathrm{~m}, y_{0}=50 \mathrm{~km}, \sigma=4.5 \mathrm{~km}$.

The model bathymetry is an idealization of the real bathymetry of the Mid-Atlantic Ridge (Fig. 1b). Fracture zone canyons are spaced at about the same along-ridge distance of order $100 \mathrm{~km}$. The ridge flanks between canyons have abyssal hill topography but no coherent incisions running across the ridge flank. Our canyon setup captures only the most prominent features of the bathymetry-abyssal hills are included again only indirectly through their effect on mixing, which we continue to parameterize as a bottom-enhanced diffusivity profile. Furthermore, real canyons can be interrupted by abyssal hill topography and typically have pronounced topography along their thalweg, whereas our simplified canyon runs uninterrupted from the base of the ridge to its crest and has a smooth bottom. Our model canyon is somewhat shallow compared to the canyon sites studied in the Brazil Basin Tracer Release Experiment (Thurnherr et al. 2005; Toole 2007) and the Dynamics of Mid-Ocean Ridge Experiment (Clément et al. 2017), where the canyon is more than $1000 \mathrm{~m}$ deep. Despite these differences, we posit that our model bathymetry captures the essential response of the subinertial flow to the presence of ridge flank canyons. By comparing this idealized simulation to observations, one can furthermore infer the importance of processes that are not included here.

We perform the same transient mixing-driven experiment started from a state of rest and uniform stratification as above. As before, the flow reaches a quasi-equilibrium in which the stratification at the ridge base and crest drift, but the flow and stratification on the ridge flanks change relatively little.

Like in the case without a canyon, submesoscale eddies develop on the ridge flanks (Fig. 6b). The eddies here develop earlier than in the case without a canyon because the along-ridge flow is perturbed by the canyon topography. This is analogous to idealized Southern Ocean simulation with and without topography (e.g., Abernathey and Cessi 2014). The eddy field is stronger here than in the simulation without a canyon (the kinetic energy is about $40 \%$ larger), and the stratification in the mixing layers on the ridge flanks remains slightly stronger.

The most conspicuous feature of this simulation, however, is that the stratification within the canyon remains very strong (Figs. 5e,f and 8a), retaining a value close to that of the interior and thus much higher than in the mixing layers on the ridge flank. This strong stratification within the canyon can largely be explained with the cross-canyon flows on the sloping canyon walls. The bottom slope of the canyon walls is much larger than the gentle slope of the ridge flank: $\theta_{c}=H_{0} / \sigma=0.09$, as opposed to $\theta=2.5 \times 10^{-3}$. This elevates the slope Burger number from $S=2 \times 10^{-3}$ to $S_{c}=2.6$, which is not small anymore. One-dimensional boundary layer theory predicts that in this regime the stratification in the outer layer remains of the same order as in the far field (Callies 2018; Fig. 9 here). This effect can also be seen in the two-dimensional simulation described in the appendix (Fig. A1). Flows up the canyon walls in an inner layer and down the canyon walls in an outer layer thus effectively maintain stratification in the canyon.

The total diffusive buoyancy flux into the canyon, however, still lightens the water there. To prevent the canyon from homogenizing from the bottom up, this tendency must be balanced by a flow advecting dense water up the large-scale ridge. But instead of unidirectional up-ridge flow at the base of the canyon, that is, along its thalweg, the along-canyon flow exhibits a bidirectional structure (Fig. 8a). On the western ridge flank, the up-ridge component of the along-canyon flow is banked slightly against the northern canyon wall, and the return flow is banked slightly against the southern canyon wall. (The banking is reversed on the eastern ridge flank.) This banking is opposite to that expected from simple Coriolis deflection of along-canyon flow. Following Dell (2013), we instead interpret these alongcanyon flows as arising as the in- and outflow of crosscanyon flow that emerges in response to the sloping ridge flank and that is blocked by the canyon walls. While the along-canyon flows are largely along isopycnals and therefore have a reduced effect on restratification, they do have a sufficiently strong cross-isopycnal component to advect dense water from the base of the ridge to balance the net diffusive buoyancy flux convergence in the canyon. The strong canyon stratification is therefore the result of the stratifying tendency of a combination of cross- and along-canyon mean flows.

The along-canyon flow has a magnitude of order $0.01 \mathrm{~m} \mathrm{~s}^{-1}$ and is thus much greater than any cross-ridge mean flow in the simulation without a canyon. This magnitude is consistent with Dell's argument for the emergence of these flows because it matches the magnitude of the along-ridge flow in the one-dimensional solution (Fig. 4c), which is turned into cross-ridge flow. The magnitude is also similar to the mean flow observed in a deep canyon on the western flank of the Mid-Atlantic Ridge near $22^{\circ} \mathrm{S}$ in the Brazil Basin Tracer Release Experiment (Thurnherr et al. 2005; Toole 2007), although these observations do not show a down-ridge return flow. In the appendix, we further substantiate the 

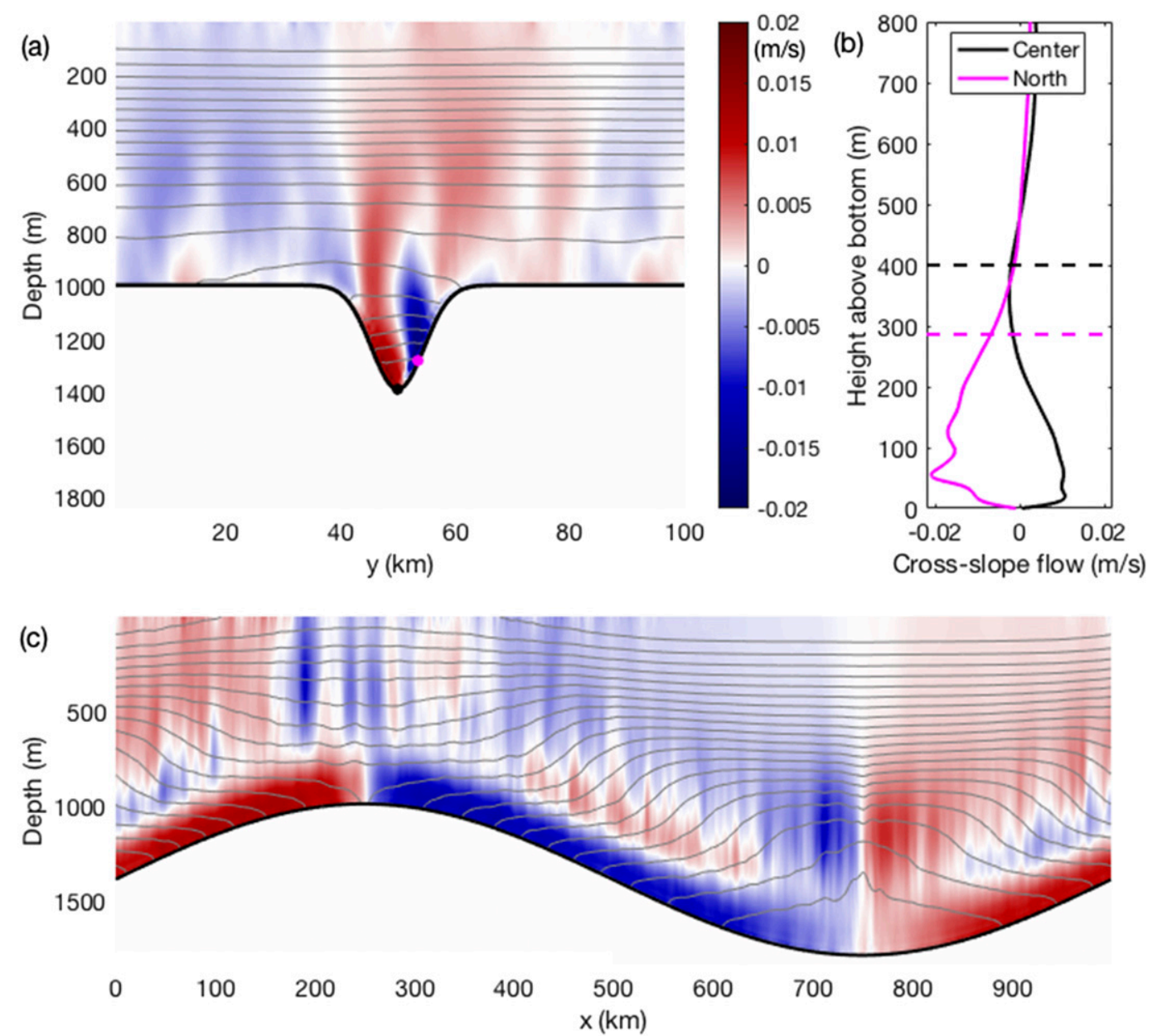

FIG. 8. The structure of the cross-ridge flow in the canyon. All pw the cross-ridge, i.e., along-canyon, flow in the three-dimensional simulation with a canyon, averaged over days 1000-2000. (a) Along-ridge section at the center of the ridge flank $(x=0)$ and (b) vertical profiles as functions of height above the bottom at the locations marked by the black and magenta dots in (a). The dashed lines mark the canyon crest. (c) Cross-ridge section at the center of the canyon $(y=50 \mathrm{~km})$. The gray contours in (a) and (c) show isopycnals.

interpretation of the along-canyon flows as arising due to the mechanism proposed by Dell (2013). We show there that these along-canyon flows are reversed if the large-scale ridge is removed, suggesting they are not generated directly by the sloping canyon walls. We also show that these flows' existence does not depend on the flow on the ridge flanks away from the canyon, suggesting the canyon flows can be understood in isolation as in Dell (2013).

A major difference between our idealized simulation and observations from real ridge flank canyons is the stratification structure (Fig. 8c). The simulated stratification in the bottom $300 \mathrm{~m}$ is similar to that in the far field and stronger than what is observed (e.g., St. Laurent et al. 2001; Thurnherr and Speer 2003). Furthermore, the simulations exhibit weak stratification in a layer around the canyon crest, leading to a staircase structure in the isopycnals-in contrast to observations, which typically show isopycnals that monotonically steepen with depth. One possible explanation for this mismatch is that our hyperviscosity damps out baroclinic instability that would otherwise develop in the weakly stratified layer overlying the canyon. ${ }^{2}$ The baroclinic eddies that would emerge at even smaller scales than

\footnotetext{
${ }^{2}$ The Richardson number in the weakly stratified layer is about $\mathrm{Ri}=10$. The growth rate of a baroclinic instability in this layer would thus be of order $\sigma=[(5 / 54) /(\mathrm{Ri}+1)]^{1 / 2}|f|=5 \times 10^{-6} \mathrm{~s}^{-1}$ (Stone 1966). The maximum growth would occur around $k=[(5 / 2) /(\mathrm{Ri}+1)]^{1 / 2}|f| / \Delta U=2.6 \times 10^{-3} \mathrm{~m}$ for an estimated shear across the layer of $\Delta U=1 \mathrm{~cm} \mathrm{~s}^{-1}$. The hyperviscous damping rate at that scale is $\nu_{4} k^{4}=1.4 \times 10^{-6} \mathrm{~s}^{-1}$, which is of the same order as the growth rate. Such an instability would thus be artificially damped by the hyperviscosity.
} 

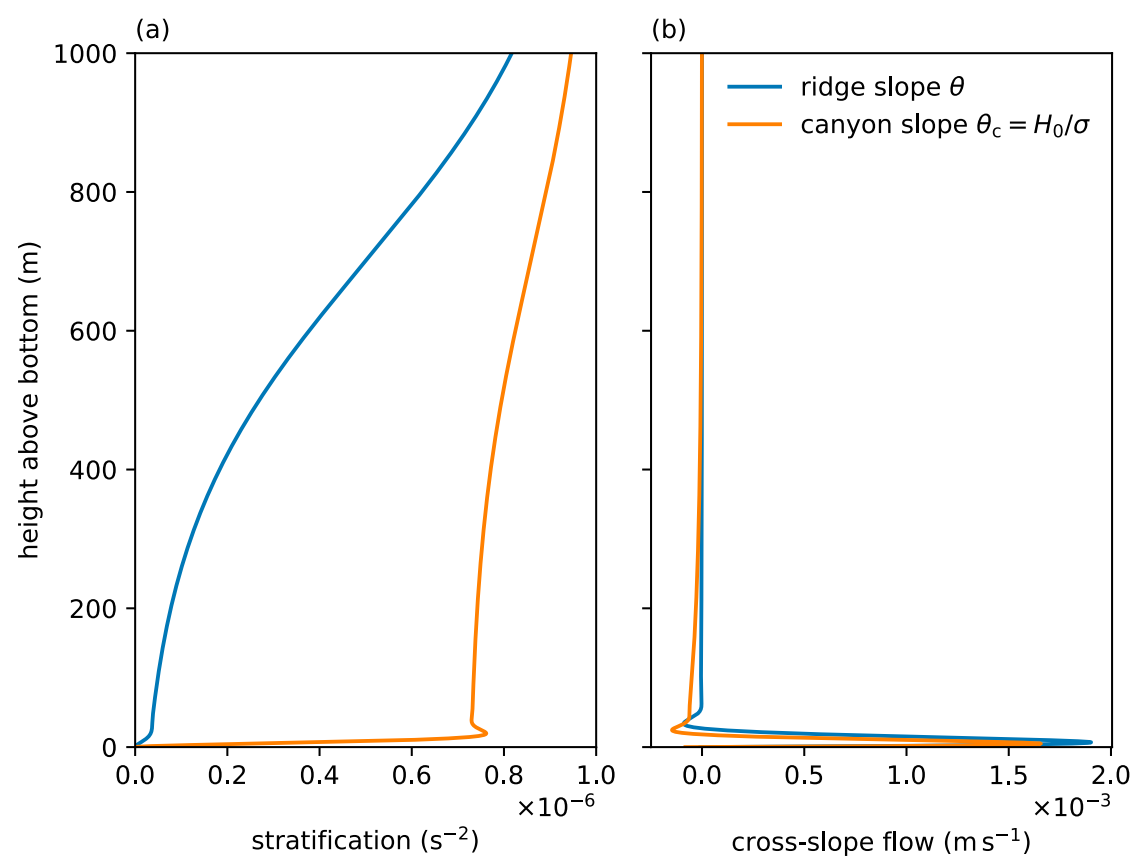

FIG. 9. Maintenance of stratification in mixing layers on the canyon walls. Shown are the analytical solutions to the steady one-dimensional dynamics from Callies (2018) for the ridge slope $\theta=2.5 \times 10^{-3}$ and for the canyon slope $\theta=H_{0} / \sigma=0.09$, i.e., for slope Burger numbers $S=2 \times 10^{-3}$ and $S_{c}=2.6$. (a) The stratification (background plus perturbation) is strongly reduced in the ridge solution, whereas it remains close to the far-field value of $10^{-6} \mathrm{~s}^{-2}$ in the canyon solution. (b) The cross-slope flow $u$ in the inner layer is of similar magnitude in the two solutions, but the outer-layer flow is stronger in the canyon solution.

those resolved in our simulation would straighten out isopycnals, increasing the stratification in the lowstratification layer and decreasing it around it (cf. Garner et al. 1992). That would bring the simulated stratification closer to what is observed. Other possible explanations for the mismatch are that our canyon walls are too steep, that the mixing field in the canyon is not well represented by our profile that is a function of height above the bottom only (cf. St. Laurent et al. 2001), that the along-canyon flows importantly interact with other topographic features such as sills or rugged canyon walls (cf. Clément et al. 2017), or that subinertial flows interact nontrivially with the tidal flow in the canyon. These possibilities should be explored in future work.

We also note that the laterally offset cross-ridge return flow found in the simulation (Fig. 8a) has not been observed in the real ocean. Available observations instead show a strong up-canyon current as the only conspicuous feature of the mean flow (e.g., Thurnherr et al. 2005). It is clear that a more realistic stratification in our simulation would also modify the buoyancy flux convergence and divergence and rearrange the alongcanyon mean flow. In addition, the mean flow could be affected by lateral turbulent momentum fluxes missing from the simulation or by differences in the width of the canyon in relation to the local deformation radius. Again, further study is needed to understand what ingredients in addition to what is included in our idealized simulation are required. It is of course also possible that the sparse observations have so far missed a down-ridge return flow.

\section{Integrated diabatic fluxes and water mass transformation}

The impact of diapycnal fluxes on the abyssal overturning circulation is often diagnosed in buoyancy coordinates. We here follow this tradition and consider two such diagnostics: the diapycnal flux integrated over isopycnals and the water mass transformation (WMT).

The diapycnal flux integrated over an isopycnal is

$$
F(b, t)=\iint_{S(b, t)} \mathbf{F}_{b} \cdot \mathbf{n} d S,
$$

where $S(b, t)$ is the isopycnal surface defined by the target buoyancy $b$ at time $t, \mathbf{n}$ is a normal unit vector of that surface (pointing to larger buoyancy), and $\mathbf{F}_{b}=-\kappa\left(N^{2}+b_{z}\right) \mathbf{z}$ is the diabatic buoyancy flux (we 
neglect small contributions from hyperdiffusion). In the real ocean and in a long-term equilibrium, $F$ must balance the buoyancy flux that the volume of water bounded by $S$ receives at the sea surface. Our transient simulations do not reach such an equilibrium because there are no surface buoyancy fluxes that could balance $F$. We still deem it useful to diagnose $F$ in our simulations, however, because it elucidates the way the different restratification processes affect how strong a diapycnal flux can be sustained. How strong a flux $F$ can be sustained for a given distribution of mixing affects what configuration the abyssal water masses and circulation would assume in equilibrium.

The WMT is defined as the convergence of $F$ in buoyancy space:

$$
T(b, t)=-\frac{\partial F}{\partial b}
$$

As shown by Walin (1982), the WMT matches the volume transport across the isopycnal defined by $b$. It is defined such that a positive $T$ corresponds to an upward volume transport. In the real ocean and in a long-term equilibrium, this transformation rate is the same as the overturning circulation across that isopycnal surface. In our simulations, $T$ describes the rate at which the volume of water bounded by $S$ shrinks. While our simulations do not reach a steady configuration with an overturning circulation, diagnosing the WMT allows us to elucidate how the different restratification processes affect the rate at which dense water is consumed.

That the integrated buoyancy flux $F$ and the WMT $T$ differ between our three simulations can be anticipated from the differences in stratification and buoyancy flux. For example, the stratification in the mixing layers is much weaker in the two-dimensional simulation than in the three-dimensional simulation without a canyon (Figs. 7a,d). The enhanced stratification produced by submesoscale eddies in the three-dimensional case enhances the buoyancy flux $-\kappa b_{z}$ in the mixing layers (Figs. 7b,e). This leads to an enhanced integrated buoyancy flux $F$ in the three-dimensional case. It should be noted, however, that around $800 \mathrm{~m}$ off the bottom the stratification is somewhat reduced in the threedimensional case, leading to a reduction of $F$. This reduction in stratification is likely due to an eddy exchange between the mixing layer and the layer above, which in addition to the restratification of the mixing layer causes a destratification of the layer above (cf. Garner et al. 1992; Lapeyre et al. 2006).

Not captured by the integral quantity $T$ are the compensating contributions to it by buoyancy fluxes that are convergent and divergent in different parts of the domain. The differences in stratification causes drastically different patterns of buoyancy flux convergence and divergence: the enhanced mixing-layer stratification in the three-dimensional simulation causes a strong dipole of convergence and divergence, whereas that dipole is weak in the two-dimensional case (Figs. $7 \mathrm{c}, \mathrm{f}$ ). In our diagnosis of WMT, we therefore split the total into contributions from buoyancy convergence and divergence (cf. Ferrari et al. 2016; Callies and Ferrari 2018b).

\section{a. Diabatic fluxes integrated over isopycnals}

We diagnose the integrated buoyancy flux from the simulations as

$$
F(b, t)=-\iint_{A(b, t)} \kappa\left(N^{2}+b_{z}\right) d x d y,
$$

where $A$ is the area of the surface $S$ projected onto the $x-y$ plane. In the two-dimensional simulation, we assume the domain to extend $L_{y}=100 \mathrm{~km}$ in the along-ridge direction to enable comparison with the three-dimensional simulations. We focus our discussion on $t=6000$ days, when the mixing-layer dynamics reach quasi-equilibrium, but we also consider aspects of the evolution over time.

To further elucidate the differences between the three cases, we split $F$ into contributions from the uniform background diffusivity $\kappa_{0}$ and the bottom-enhancement $\kappa_{1} e^{-(z+H) / h}$. These interior and boundary contributions $F_{I}$ and $F_{B}$ linearly add up to the full flux: $F=F_{I}+F_{B}$.

In all simulations, the integrated buoyancy flux $F$ peaks around $b=-5 \times 10^{-4} \mathrm{~m} \mathrm{~s}^{-2}$, corresponding to isopycnals that incrop on the upper part of the ridge flanks (Fig. 10a). The peak flux magnitude increases from $5.1 \mathrm{~m}^{4} \mathrm{~s}^{-3}$ in the two-dimensional simulation to $5.9 \mathrm{~m}^{4} \mathrm{~s}^{-3}$ in the three-dimensional simulation without a canyon and to $7.2 \mathrm{~m}^{4} \mathrm{~s}^{-3}$ in the three-dimensional simulation with a canyon. This increase in the peak flux reflects the increased stratification in the three-dimensional simulations and the added water with strong stratification in the case with a canyon. As expected, stronger restratification enables a larger integrated buoyancy flux.

The interior contributions $F_{I}$ are very similar between the three cases (Fig. 10a). This is expected because this interior contribution is dominated by fluxes away from the mixing layer, where the stratification is close to the initial stratification and the differences between the three cases are small (Figs. 7a,d). For isopycnals that incrop on the centers of the ridge flanks, the interior contribution is approximately $F_{I} \approx-\kappa_{0} N^{2} L_{x} L_{y} / 2=$ $-3 \mathrm{~m}^{4} \mathrm{~s}^{-3} F_{\mathrm{I}} \approx-\kappa_{0} N^{2} L_{x} L_{y} / 2=-3 \mathrm{~m}^{4} \mathrm{~s}^{-3}$, where $L_{x} L_{y} / 2$ is roughly the area of isopycnals in the interior. For isopycnals that incrop on the ridge flanks, the interior contribution depends roughly linearly on buoyancy because the area covered by the isopycnals depends roughly linearly on depth and thus on buoyancy. 

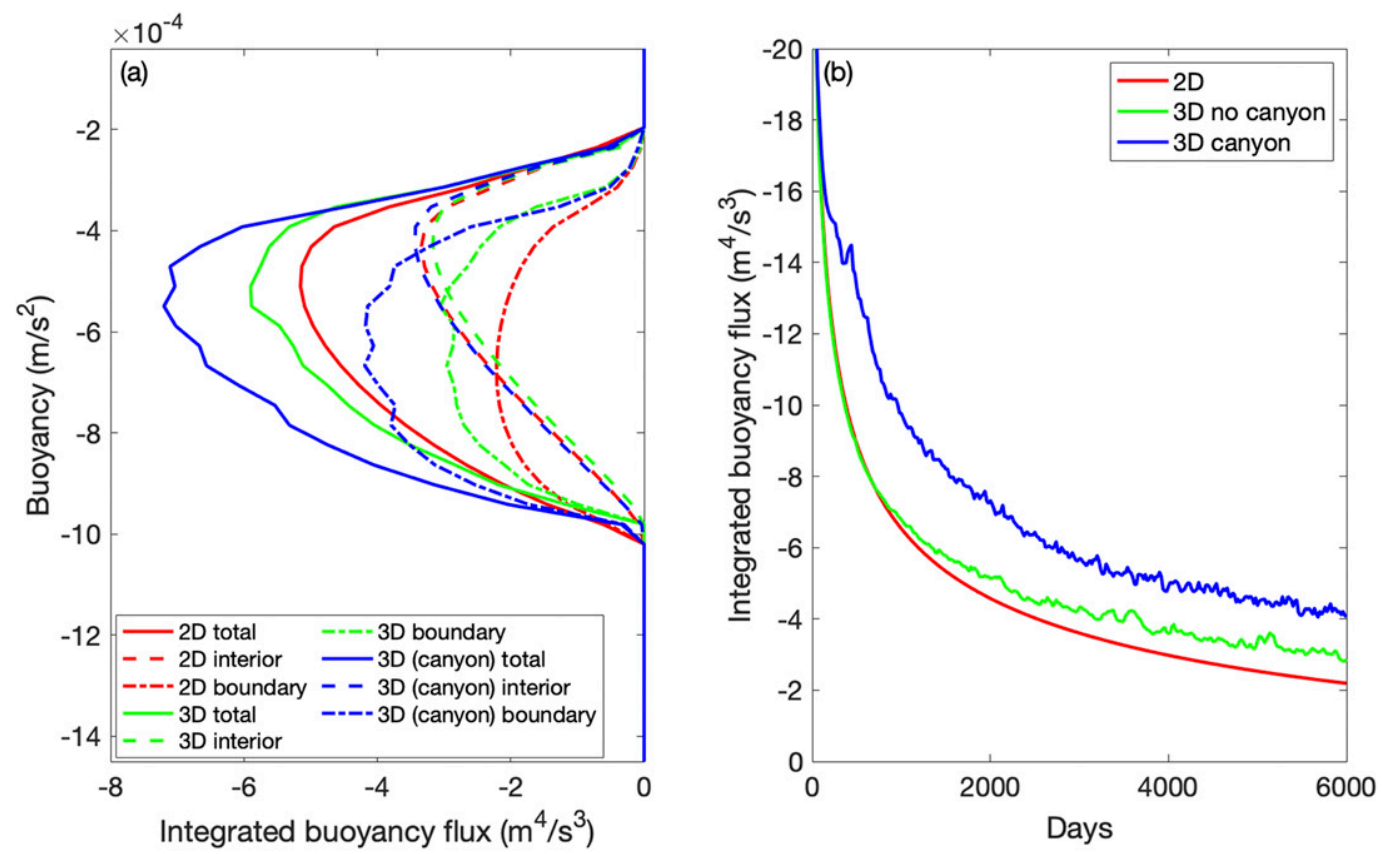

FIG. 10. The integrated buoyancy flux $F$ and its evolution in the three simulations. (a) The integrated buoyancy fluxes $F$ (total) and their decomposition into interior and boundary contributions $F_{B}$ and $F_{I}$ at day 6000 . (b) Evolution of the boundary contribution $F_{B}$ for an isopycnal incropping on the ridge flanks $\left(b=-6.2 \times 10^{-4} \mathrm{~m} \mathrm{~s}^{-2}\right)$.

This effect is thus governed by the ridge's hypsometry (e.g., McDougall 1989; Holmes et al. 2018).

The boundary contribution $F_{B}$ is where almost all of the differences between the simulations originate (Fig. 10a). In all three cases, $F_{B}$ is largely constant over the buoyancy range corresponding to isopycnals that incrop on the ridge flanks. The flux magnitude increases from $2.2 \mathrm{~m}^{4} \mathrm{~s}^{-3}$ in the two-dimensional case to $3.1 \mathrm{~m}^{4} \mathrm{~s}^{-3}$ in the three-dimensional case without a canyon and $4.2 \mathrm{~m}^{4} \mathrm{~s}^{-3}$ in the case with a canyon.

These differences between the three cases are expected because the boundary contribution $F_{B}$ depends sensitively on the stratification in mixing layers (Garrett 1990, 2001). As isopycnals tilt more strongly toward the bottom and the mixing-layer stratification weakens, not only does this weaken the local buoyancy flux, it also reduces the horizontal area covered by isopycnal surfaces. Neglecting buoyancy anomaly variations in the plane of the slope, the boundary contribution to the integrated buoyancy flux can be written in terms of an integral in the slope-normal direction:

$$
\begin{aligned}
F_{B}= & -L_{y} \int_{0}^{\infty} \kappa_{1} e^{-z / h \cos \theta} N^{2}\left[\sin ^{2} \theta\right. \\
& \left.+\left(\frac{N^{2} \cos \theta+b_{\dot{z}}}{N^{2} \cos \theta}\right)^{2} \cos ^{2} \theta\right] \frac{d \dot{z}}{\sin \theta},
\end{aligned}
$$

where the integration over a finite isopycnal was replaced by an integration into the far field, which incurs only a small error because the integrand decays rapidly with height. We here again assume an along-slope domain width of $L_{y}=100 \mathrm{~km}$. For the small abyssal slope angles $\theta$, the first term in square brackets is generally negligible. This equation shows that the integrated buoyancy flux depends on the square of the mixing-layer stratification-reflecting the dependence of the integrated flux on both the stratification and the area covered by the isopycnal surface.

Garrett $(1990,2001)$ defined the efficiency of boundary mixing $I$ as the ratio between $F_{B}$ and the value $F_{B}$ would assume if the stratification were constant all the way to the boundary (our initial conditions). Setting $b_{z}=0$ in (17) yields the constant-stratification reference value $F_{B}=-L_{y} \kappa_{1} N^{2} h \cot \theta=-16 \mathrm{~m}^{4} \mathrm{~s}^{-3}$. We take the reference $F_{B}$ in our two- and three-dimensional simulations to be twice this value for isopycnals incropping on the ridge flanks because these isopycnals encounter two mixing layers. With this definition of the efficiency, we obtain $I=7 \%$ for the two-dimensional case, $I=10 \%$ for the three-dimensional case without a canyon, and $I=13 \%$ for the three-dimensional case with a canyon, all evaluated at $t=6000$ days and for isopycnals incropping on the ridge flanks $\left(b=-6.2 \times 10^{-4} \mathrm{~m}^{2} \mathrm{~s}^{-1}\right)$.

The difference between the two-dimensional case and the three-dimensional case without a canyon is smaller 
than what might be expected from the marked difference in mixing-layer stratification (Figs. 7a,d) and the sensitive dependence of $F_{B}$ on that stratification suggested by (17). The difference stemming from the mixing layer that is more strongly stratified in the presence of eddies is partially compensated by contributions from around $800 \mathrm{~m}$ off the bottom, where the stratification is stronger without the eddies. The result is a relatively modest difference between the two cases at this time.

The difference between these two cases, however, increases over time (Fig. 10b). One might expect the two-dimensional simulation to tend toward the steady one-dimensional solution, which has an efficiency $I=3 \%$. The eddy restratification in the three-dimensional case should prevent a decrease to such a small value, and one might expect the difference between the two cases to further increase as time goes on.

The efficiency substantially increases as we add a canyon to the three-dimensional simulation. This increase arises because isopycnals flatten out within the canyon and thus provide strong stratification and a large area on which bottom-enhanced mixing can act (Fig. 8c). This is a remarkable increase in the integrated flux, considering the canyon covers only about a fifth of the ridge flank area. The increase arises primarily from contributions in the canyon-the flux is also modestly increased over the ridge flanks away from the canyon, but the contribution is minor. As noted above, however, the stratification within the canyon is unrealistically strong, so the increase in efficiency diagnosed from the simulation with a canyon is likely an overestimate.

To further put these efficiencies into context, we calculate the efficiency of the stratification profile observed in the Brazil basin. We use the one-dimensional outerlayer solution

$$
\begin{aligned}
N^{2} \cos \theta+b_{z}= & N^{2} \cos \theta\left(\frac{\kappa_{0}}{\kappa_{0}+\kappa_{1} e^{-\dot{z} / h \cos \theta}}\right. \\
& \left.+\frac{\kappa_{1} e^{-z / h \cos \theta}}{\kappa_{0}+\kappa_{1} e^{-z / h \cos \theta}} \frac{S \operatorname{Pr}}{1+S \operatorname{Pr}}\right),
\end{aligned}
$$

which Callies (2018) fit to observations considering $S \operatorname{Pr} /(1+S \operatorname{Pr})$ a free parameter. The best fit to the observed profile was obtained for $S \operatorname{Pr} /(1+S \operatorname{Pr})=0.35$. When plugged into (17), this yields $I=18 \%$. This number is larger than the efficiencies obtained in any of our simulations. Possible explanations are that the simulated eddies are artificially damped by insufficient resolution and excessive hyperviscosity, that interior and large-scale processes neglected here (e.g., the planetary potential vorticity gradient or a nonconstant interior stratification) play a role in setting mixing-layer stratification, or that the neglected small-scale abyssal hill topography importantly modifies the subinertial circulation on ridge flanks. These possibilities should be explored in future work.

\section{b. Water mass transformation}

To examine the volume transport across different isopycnals, we now turn to the WMT rate $T$. Since $T=-\partial F / \partial b$, changes in the integrated flux $F$ with buoyancy translate into WMT (Fig. 11a). The WMT is positive at low buoyancy, that is, in the trough of the ridge system, and it is negative at high buoyancy, that is, near the surface and ridge crest. The integral of the WMT over all buoyancy classes is zero because there is no buoyancy flux across the domain boundaries.

It is clear from the above discussion of the integrated flux $F$ that the peak positive WMT arises from the bottom-intensified part of the mixing, which contributes almost all of the flux gradient in the near-bottom buoyancy classes (Fig. 10a). The WMT at intermediate buoyancy classes arises primarily from the interior part of the mixing and the associated hypsometric effect. The negative WMT near the top of the domain has comparable contributions from the two components.

The differences in the integrated flux $F$ between the three simulations translate into differences in WMT (Fig. 11a). The near-bottom WMT, that is, the rate of dense bottom water consumption, is lowest in the twodimensional case, intermediate in the three-dimensional case without a canyon, and largest in the three-dimensional case with a canyon. Yet, the differences between the three cases are modest: the peak WMT is $2.6 \times 10^{4} \mathrm{~m}^{3} \mathrm{~s}^{-1}$ in the two-dimensional case and $3.2 \times 10^{4} \mathrm{~m}^{3} \mathrm{~s}^{-1}$ in the three-dimensional case with a canyon.

Qualitative differences between the three cases arise when considering the contributions to WMT from convergences and divergences of buoyancy fluxes. This decomposition of the net $T(b, t)$ is defined as

$$
T^{ \pm}(b, t)=-\frac{\partial}{\partial b} \iiint_{V^{ \pm}(b, t)} \nabla \cdot \mathbf{F}_{b} d x d y d z,
$$

where $V^{ \pm}(b, t)$ are the volumes of water below the isopycnal surface $S(b, t)$ restricted to places with positive or negative buoyancy flux convergence, respectively (Figs. 7c,f; cf. Ferrari et al. 2016; Callies and Ferrari 2018b). Below the surface layers, there is very little buoyancy flux divergence in the two-dimensional simulation, whereas the positive net WMT in the two threedimensional simulations arises as a residual between positive and negative contributions (Fig. 11b). This WMT dipole, a hallmark of bottom-intensified mixing, arises only if the stratification in mixing layers is maintained. 

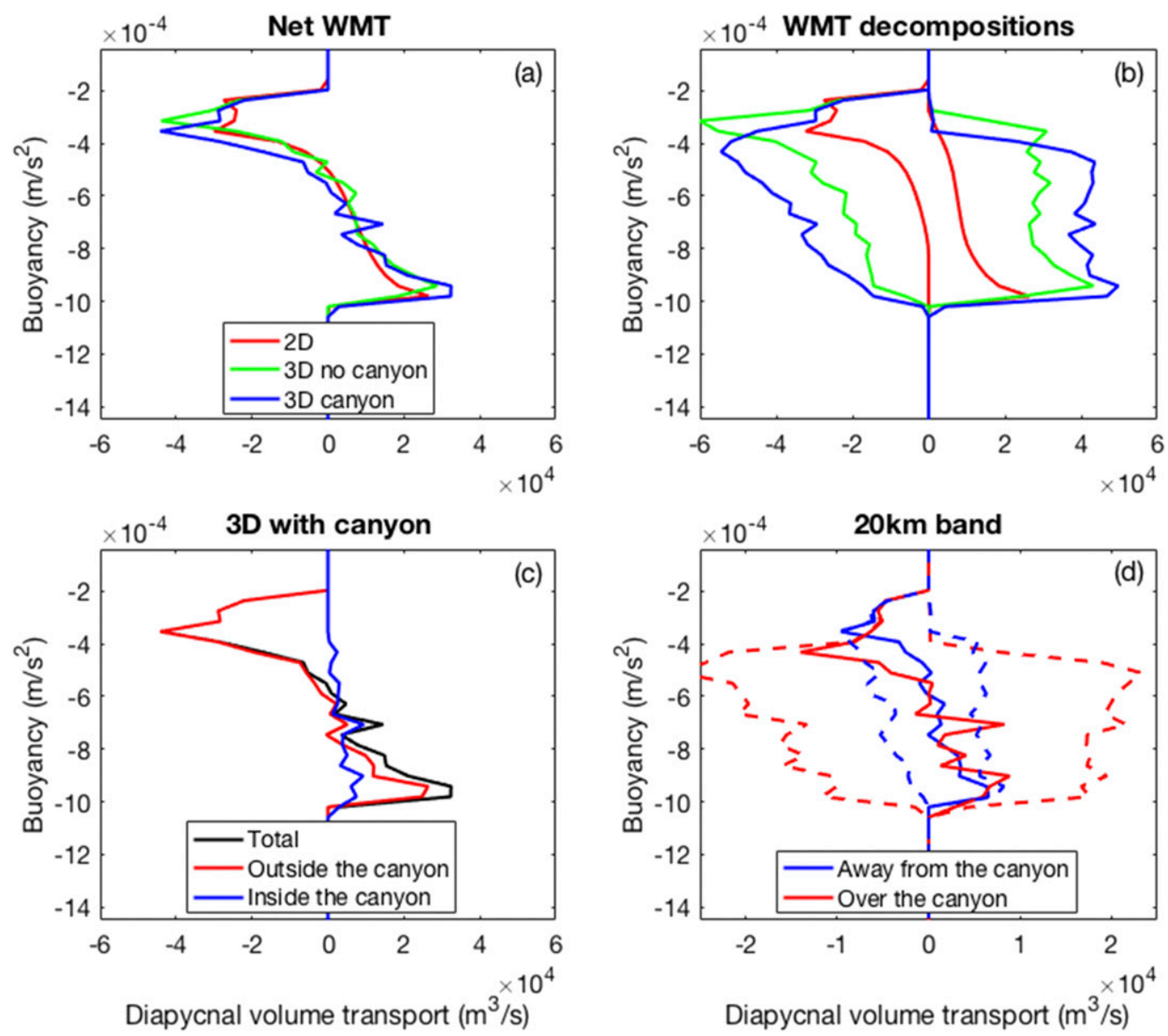

FIG. 11. Comparison of water mass transformation rates between the three simulations at day 6000. (a) The net WMT $T(b)$. (b) Decomposition of the net WMT into contributions from buoyancy flux convergences and divergences $T^{ \pm}(b)$. (c) Contributions to the net WMT from inside and outside of the canyon, diagnosed from the simulation with a canyon. (d) Comparison of the WMT from bands over and away from the canyon (solid lines), both diagnosed from the simulation with a canyon, as well as the decomposition into contributions from buoyancy flux convergences and divergences (dashed lines).

Separating the WMT in the three-dimensional simulation with a canyon into contributions from inside and outside the canyon, we find that the additional contribution from inside the canyon is of similar magnitude as the difference between the simulations with and without a canyon (Fig. 11c). Here we define "inside the canyon" as the volume of water below the ridge, that is, as the volume of water added to the domain when adding the canyon topography in (13).

Another way to quantify the contribution from the canyon is to compare the WMT in a $20-\mathrm{km}$-wide band above the canyon with the WMT in a $20-\mathrm{km}$-wide band away from the canyon (Fig. 11d). We define the canyon band as $40 \mathrm{~km}<y<60 \mathrm{~km}$ and choose the reference band as far away from the canyon as possible: $y<10 \mathrm{~km}$ and $y>90 \mathrm{~km}$. The net WMT is comparable but somewhat stronger over the canyon. A qualitative difference again emerges only when considering the positive and negative contributions to WMT separately. The strong stratification and the resulting dipole in buoyancy flux convergence and divergence causes the compensating positive and negative contributions to the WMT to be much larger over the canyon than away from it. As discussed above, however, the stratification in the canyon is unrealistically strong, so the diagnosed strength of the WMT dipole over the canyon is likely an overestimate.

Finally, we note that the simulated peak WMT of $0.035 \mathrm{~Sv}(100 \mathrm{~km})^{-1}$ along-ridge distance appears to be too weak to close the abyssal water mass budget of the Brazil basin. Dividing our WMT in half because the real Brazil basin is bounded by only one ridge flank, assuming an along-ridge distance of $3000 \mathrm{~km}$, and ignoring changes in the ridge geometry, mixing rates, inertial frequency, etc., we arrive at a total WMT of $0.5 \mathrm{~Sv}$. 
This is substantially less than the $4 \mathrm{~Sv}$ of AABW upwelling estimated by Hogg et al. (1982). We do not expect this estimate to be affected by the unrealistic narrowness of our ridge because the net WMT is set by the divergence of the boundary contribution $F_{B}$, which does not scale with the width of the ridge.

In summary, the net WMT in our simulations shows relatively little sensitivity to the strength of mixing-layer restratification, and the WMT diagnosed from the simulations is weak compared to observations. It thus appears that effects neglected here-such as nonconstant interior stratification, deviations from the simple ridge geometry, and the geography of mixing-may play an important role in setting the net WMT. It is clear, however, that bottom-intensified mixing produces a WMT dipole only if stratification is maintained in mixing layers.

\section{Discussion}

The simulations demonstrate that submesoscale baroclinic eddies and mean flow advection can maintain stratification over the ridge flanks and inside the ridgeflank canyons, which is crucial for the effective consumption of dense bottom waters in such mid-ocean ridge systems. Several assumptions and idealizations have been made in this study that need to be considered in interpreting the results presented above.

First, due to the limitation of computing power, the grid spacing employed in the numerical model is not able to resolve all the submesoscale baroclinic eddies. The underresolved submesoscale eddies not only fail to smooth out the stratification inside the canyon (section 5) but may also render the restratification over the broader ridge flanks too weak. The corresponding buoyancy flux and WMT rates with refined grid resolution need to be examined in more detail in order to more accurately extrapolate to the larger midocean ridge system.

Second, the abyssal hill topography is not explicitly resolved in the model. Its role in facilitating the nearbottom turbulent mixing has been simply represented in the bottom-intensified mixing profile. These small-scale topographic features may also support local boundary layer systems and steer the restratifying mean flows, in addition to the relatively large-scale dynamics caused by the parameterized bottom-intensified mixing considered here. It remains unclear what effect such more convoluted flow paths would have on the stratification in mixing layers. It should further be noted that abyssal hills are typically aligned with the ridge axis, so they may also hinder rather than enable cross-ridge flow and attendant restratification.
Third, the current model simulations do not allow the mixing profile to vary by location. Location-dependent processes may change the magnitude and functional form of this mixing profile. As pointed out in previous studies, subinertial up-canyon flows, as simulated here, may influence the propagation and breaking of internal waves inside the canyon (Toole 2007; Clément and Thurnherr 2018). This could potentially create strong mixing in the middle of the water column and modify the mixing profile. Moreover, hydraulically controlled mixing events have been reported in observations: subinertial currents flow over sills in the canyon and create locally enhanced mixing (e.g., Clément et al. 2017). More realistic mixing profiles that could reflect local dynamics such as those discussed above or even the resolution of such dynamics with much finer grid spacing are needed in future studies.

Fourth, both nonuniform interior stratification and meridional variations in the inertial frequency have been neglected. Both effects introduce lateral variations in the mixing-layer properties and can thus cause coupling between the mixing layer and the interior. How that affects the mixing-layer stratification remains unexplored. Preliminary work suggests that nonuniform interior stratification indeed affects mixing-layer flow and the net WMT (H. Drake 2019, personal communication).

\section{Conclusions}

Bottom-intensified turbulence in abyssal mixing layers erodes stratification, so stratification must be maintained in order to sustain diabatic fluxes into the abyss. The three numerical simulations presented in this study elucidate different restratification mechanisms in mid-ocean ridge systems, which likely play a key role in the consumption of AABW. A two-dimensional simulation of a large-scale ridge isolates cross-ridge mean flow restratification, a three-dimensional simulation of a large-scale ridge additionally allows restratification by submesoscale baroclinic eddies, and a three-dimensional simulation of a largescale ridge with an idealized fracture zone canyon additionally allows restratification by mean flows induced by the canyon topography.

The flanks of a two-dimensional ridge behave like a uniform slope: cross-ridge mean flows are weak because rotation turns these flows into geostrophically balanced along-ridge flow. Consequently, these mean flows cannot advect enough dense water up the slope and light water down the slope to balance the diffusive buoyancy tendencies. Mixing-layer stratification erodes rapidly, and buoyancy fluxes into the abyss become weak. Compared to the one-dimensional uniform-slope case, cross-slope 

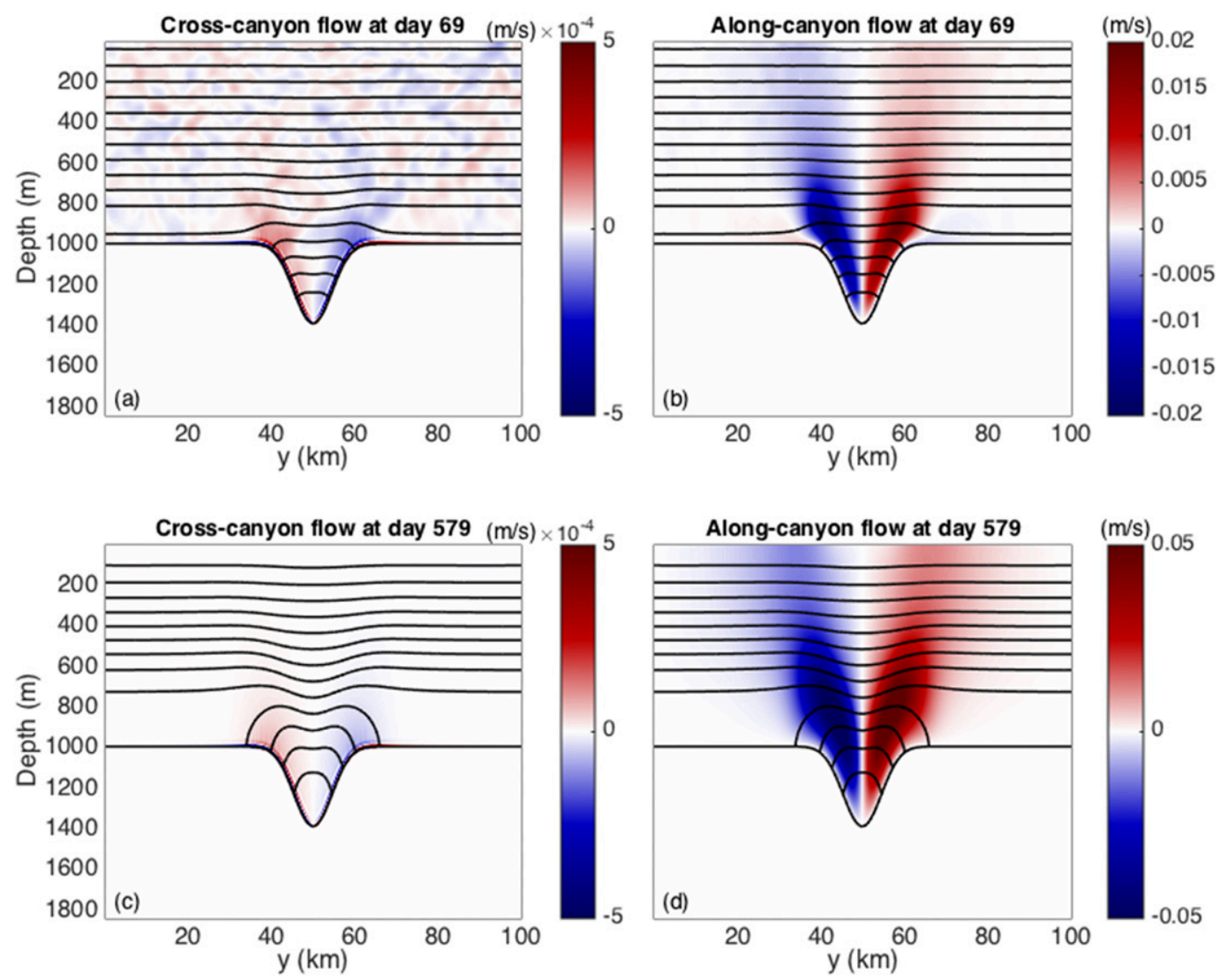

FIG. A1. Flows in a two-dimensional canyon without the large-scale ridge. (a) Cross-canyon flow at day 69, (b) along-canyon flow at day 69, (c) cross-canyon flow at day 579, and (d) along-canyon flow at day 579. The shading shows velocities, and black contours are isopycnals.

mean flows are even weaker over the flanks of a twodimensional ridge because the along-ridge flow in the far field adjusts more readily. This causes weaker crossridge Ekman transport and further weakens the restratification of mixing layers.

A third dimension allows restratification by submesoscale baroclinic eddies, again like on uniform slopes. In response to the erosion of mixing-layer stratification and the buildup of available potential energy on the ridge flanks, baroclinic instability ensues and the resulting eddies laterally slide dense under light water (Callies 2018; Wenegrat et al. 2018). This submesoscale restratification allows the maintenance of both a larger buoyancy flux into the abyss and a strong dipole in WMT.

Finally, the walls of a fracture zone canyon have slope Burger numbers of order unity, which allows crosscanyon mean flows to maintain stratification on the sloping canyon walls. In addition, strong mean flows running along the thalweg of the canyon advect dense water up the canyon, balancing the buoyancy flux convergence there. The flow along the canyon axis has a large along-isopycnal component, however, and it has bidirectional structure with a laterally offset return flow (cf. Dell 2013). Together, the cross- and along-canyon mean flows maintain strong stratification throughout the canyon and allow bottom-enhanced mixing to produce a strong dipole of WMT there. In our idealized simulation, the canyon contributes significantly to the total buoyancy flux into the abyss, but the canyon contribution is likely overestimated as the stratification in the canyon is unrealistically strong. Fracture zone canyons only cover a small portion of the area of ridge flanks-whether they make an outsized contribution to the consumption of $\mathrm{AABW}$ remains open and warrants further investigation.

The importance of submesoscale eddies and possibly canyon topography in maintaining the boundary contribution to the buoyancy flux into the abyss and the associated dipole in WMT suggests that their effect should be incorporated into large-scale models of the abyssal circulation. Submesoscale restratification of abyssal mixing layers could be parameterized in coarse-resolution models, similar to how submesoscale restratification of 

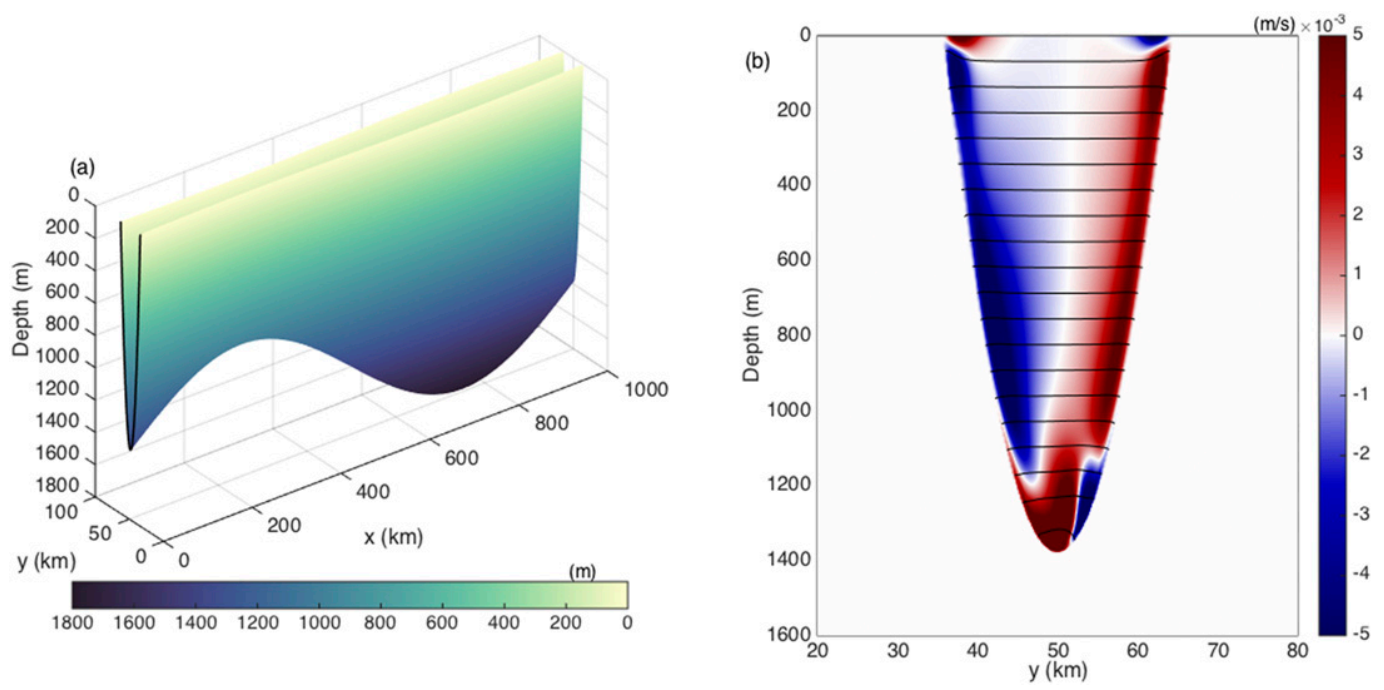

FIG. A2. Simulation without the ridge flanks, which isolates the canyon effects. (a) Model topography, showing the isolated deep canyon. (b) Cross-ridge flow at day 35 (shading) and isopycnals (black contours).

the surface mixed layer is parameterized (Fox-Kemper et al. 2011). Parameterizations of subgrid canyon flow are also conceivable. Including these processes may be crucial for accurately capturing the patterns and rates of AABW consumption.

Acknowledgments. We thank Beverley McKeon, Andrew Stewart, Andrew Thompson, and Andreas Thurnherr for helpful discussions. This work was funded by National Science Foundation Grant OPP-1644172.

\section{APPENDIX}

\section{Extra Simulations for the Lateral Dipole of Cross-Ridge Flow in a Fracture Zone Canyon}

Here we substantiate the interpretation that the lateral dipole of cross-ridge flow in a fracture zone canyon is produced by the mechanism described by Dell (2013) (Fig. 8 here). We present two additional simulations (i) to exclude the possibility that the dipolar flow is the result of boundary layer flow induced by the canyon walls and (ii) to confirm that the cross-ridge flow is produced within the canyon and is not the result of interaction with the flow on the ridge flank outside of the canyon.

To ascertain that the cross-ridge flow in the canyon is due to the large-scale ridge, we consider a twodimensional simulation with the large-scale ridge removed. The two-dimensional domain is a slice through the three-dimensional domain in the center of the western ridge flank $(x=0)$, yet without the slope of the ridge flank (Fig. 2b). We perform the same experiment started from uniform stratification and rest. The bottom-enhanced mixing produces isopycnals that tilt over the sloping canyon walls, and cross- and along-canyon flow develops (Fig. A1). The flow is antisymmetric with respect to the canyon axis. The along-canyon flow resembles the cross-ridge flow in the three-dimensional simulation above the crest of the canyon (Fig. 8). In the canyon, dipolar along-canyon flow does emerge, but it has the opposite sign of flow in the three-dimensional solution. This suggests that it is not the boundary layer flows produced by sloping canyon walls that give rise to the cross-ridge mean flow in the three-dimensional system.

The three-dimensional setup considered in the main text allows along-ridge flow over the ridge flanks to flow into the canyon and interact with the up-ridge flow there. Horizontal convergence upstream of the ridge and divergence downstream of the ridge could tilt isopycnals and thus lead to a cross-canyon dipole of up-ridge flow. To exclude this possibility, we consider an additional three-dimensional simulation that isolates the processes inside the canyon. We extend the canyon walls all the way up to the top of the domain, that is, we eliminate the ridge flanks entirely (Fig. A2a). We replace the Gaussian canyon in (13) with a parabolic canyon:

$$
H_{p}(y)=H_{0}\left[1-A\left(y-y_{0}\right)^{2}\right],
$$

with $A=1.7 \times 10^{-8} \mathrm{~m}^{-2}$ and $y_{0}=50 \mathrm{~km}$. In the same transient setup as above, we recover the lateral dipole of cross-ridge flow at the base of the canyon, with the banking as in the simulation discussed in the main text (Fig. A2b). This confirms that the ridge flank flow has 
no leading-order effect on the up-ridge flow inside the canyon.

\section{REFERENCES}

Abernathey, R., and P. Cessi, 2014: Topographic enhancement of eddy efficiency in baroclinic equilibration. J. Phys. Oceanogr., 44, 2107-2126, https://doi.org/10.1175/JPO-D-14-0014.1.

Burns, K. J., G. M. Vasil, J. S. Oishi, D. Lecoanet, and B. P. Brown, 2019: Dedalus: A flexible framework for numerical simulations with spectral methods. ArXiv, 40 pp., https://arxiv.org/ abs/1905.10388.

Callies, J., 2018: Restratification of abyssal mixing layers by submesoscale baroclinic eddies. J. Phys. Oceanogr., 48, 1995-2010, https://doi.org/10.1175/JPO-D-18-0082.1.

— , and R. Ferrari, 2018a: Baroclinic instability in the presence of convection. J. Phys. Oceanogr., 48, 45-60, https://doi.org/ 10.1175/JPO-D-17-0028.1.

— bottom-intensified mixing on slopes. J. Phys. Oceanogr., 48, 1257-1282, https://doi.org/10.1175/JPO-D-17-0125.1.

Clément, L., and A. M. Thurnherr, 2018: Abyssal upwelling in midocean ridge fracture zones. Geophys. Res. Lett., $\mathbf{4 5}$, 2424-2432, https://doi.org/10.1002/2017GL075872.

$\longrightarrow,-$, and L. C. St. Laurent, 2017: Turbulent mixing in a deep fracture zone on the Mid-Atlantic Ridge. J. Phys. Oceanogr., 47, 1873-1896, https://doi.org/10.1175/JPO-D-16-0264.1.

de Lavergne, C., G. Madec, J. Le Sommer, A. G. Nurser, and A. C. Naveira Garabato, 2016: On the consumption of Antarctic Bottom Water in the abyssal ocean. J. Phys. Oceanogr., 46, 635-661, https://doi.org/10.1175/JPO-D-14-0201.1.

Dell, R. W., 2013: Boundary layer dynamics and deep ocean mixing in Mid-Atlantic Ridge canyons. Ph.D. thesis, Massachusetts Institute of Technology and Woods Hole Oceanographic Institution, 163 pp., https://doi.org/10.1575/1912/5740.

—_, and L. Pratt, 2015: Diffusive boundary layers over varying topography. J. Fluid Mech., 769, 635-653, https://doi.org/ 10.1017/jfm.2015.88.

Ferrari, R., 2014: What goes down must come up. Nature, 513, 179-180, https://doi.org/10.1038/513179a.

—_, A. Mashayek, T. J. McDougall, M. Nikurashin, and J.-M. Campin, 2016: Turning ocean mixing upside down. J. Phys. Oceanogr., 46, 2239-2261, https://doi.org/10.1175/JPO-D15-0244.1.

Fox-Kemper, B., R. Ferrari, and R. Hallberg, 2008: Parameterization of mixed layer eddies. Part I: Theory and diagnosis. J. Phys. Oceanogr., 38, 1145-1165, https://doi.org/10.1175/2007JPO3792.1.

_ III: Implementation and impact in global ocean climate simulations. Ocean Modell., 39, 61-78, https://doi.org/10.1016/ j.ocemod.2010.09.002.

Garner, S. T., N. Nakamura, and I. M. Held, 1992: Nonlinear equilibration of two-dimensional Eady waves: A new perspective. J. Atmos. Sci., 49, 1984-1996, https://doi.org/10.1175/ 1520-0469(1992)049<1984:NEOTDE >2.0.CO;2.

Garrett, C., 1979: Comment on 'Some evidence for boundary mixing in the deep ocean' by Laurence Armi. J. Geophys. Res., 84, 5095, https://doi.org/10.1029/JC084iC08p05095.

_ 1990: The role of secondary circulation in boundary mixing. J. Geophys. Res., 95, 3181-3188, https://doi.org/10.1029/ JC095iC03p03181.

_ 1991: Marginal mixing theories. Atmos.-Ocean, 29, 313-339, https://doi.org/10.1080/07055900.1991.9649407.
- 2001: An isopycnal view of near-boundary mixing and associated flows. J. Phys. Oceanogr., 31, 138-142, https://doi.org/ 10.1175/1520-0485(2001)031<0138:AIVONB > 2.0.CO;2.

_ , P. MacCready, and P. Rhines, 1993: Boundary mixing and arrested Ekman layers: Rotating stratified flow near a sloping boundary. Annu. Rev. Fluid Mech., 25, 291-323, https:// doi.org/10.1146/annurev.f1.25.010193.001451.

Gent, P. R., J. Willebrand, T. J. McDougall, and J. C. McWilliams, 1995: Parameterizing eddy-induced tracer transports in ocean circulation models. J. Phys. Oceanogr., 25, 463-474, https://doi.org/10.1175/1520-0485(1995)025<0463:PEITTI> 2.0.CO;2.

Hogg, N. G., and W. B. Owens, 1999: Direct measurement of the deep circulation within the Brazil Basin. Deep-Sea Res. II, 46 , 335-353, https://doi.org/10.1016/S0967-0645(98)00097-6.

—, P. Biscaye, W. Gardner, and W. J. Schmitz Jr., 1982: On the transport and modification of Antarctic Bottom Water in the Vema Channel. J. Mar. Res., 40 (23), 1-263.

Holmes, R. M., C. de Lavergne, and T. J. McDougall, 2018: Ridges, seamounts, troughs, and bowls: Topographic control of the dianeutral circulation in the abyssal ocean. J. Phys. Oceanogr., 48, 861-882, https://doi.org/10.1175/JPO-D-17-0141.1.

,$- \ldots$, and -2019 : Tracer transport within abyssal mixing layers. J. Phys. Oceanogr., 49, 2669-2695, https://doi.org/10.1175/ JPO-D-19-0006.1.

Lapeyre, G., P. Klein, and B. L. Hua, 2006: Oceanic restratification forced by surface frontogenesis. J. Phys. Oceanogr., 36, 1577-1590, https://doi.org/10.1175/JPO2923.1.

Ledwell, J., E. Montgomery, K. Polzin, L. S. Laurent, R. Schmitt, and J. Toole, 2000: Evidence for enhanced mixing over rough topography in the abyssal ocean. Nature, 403, 179-182, https:// doi.org/10.1038/35003164.

Lumpkin, R., and K. Speer, 2007: Global ocean meridional overturning. J. Phys. Oceanogr., 37, 2550-2562, https://doi.org/ 10.1175/JPO3130.1.

MacKinnon, J. A., and Coauthors, 2017: Climate process team on internal wave-driven ocean mixing. Bull. Amer. Meteor. Soc., 98, 2429-2454, https://doi.org/10.1175/BAMS-D-16-0030.1.

Marshall, J., A. Adcroft, C. Hill, L. Perelman, and C. Heisey, 1997: A finite-volume, incompressible Navier Stokes model for studies of the ocean on parallel computers. J. Geophys. Res., 102, 5753-5766, https://doi.org/10.1029/96JC02775.

McDougall, T. J., 1989: Dianeutral advection. Parameterization of Small-Scale Processes: Proc. Fifth 'Aha Huliko'a Hawaiian Winter Workshop, Honolulu, HI, University of Hawai'i at Mānoa, 289-315.

Munk, W. H., 1966: Abyssal recipes. Deep-Sea Res. Oceanogr. Abstr., 13, 707-730, https://doi.org/10.1016/0011-7471(66) 90602-4.

Nikurashin, M., and S. Legg, 2011: A mechanism for local dissipation of internal tides generated at rough topography. J. Phys. Oceanogr., 41, 378-395, https://doi.org/10.1175/ 2010JPO4522.1.

Phillips, O., 1970: On flows induced by diffusion in a stably stratified fluid. Deep-Sea Res., 17, 435-443, https://doi.org/10.1016/ 0011-7471(70)90058-6.

—_, J.-H. Shyu, and H. Salmun, 1986: An experiment on boundary mixing: mean circulation and transport rates. J. Fluid Mech., 173, 473-499, https://doi.org/10.1017/ S0022112086001234.

Polzin, K., J. Toole, J. Ledwell, and R. Schmitt, 1997: Spatial variability of turbulent mixing in the abyssal ocean. Science, $\mathbf{2 7 6}$, 93-96, https://doi.org/10.1126/science.276.5309.93. 
Primeau, F. W., and M. Holzer, 2006: The ocean's memory of the atmosphere: Residence-time and ventilation-rate distributions of water masses. J. Phys. Oceanogr., 36, 1439-1456, https://doi.org/10.1175/JPO2919.1.

Sarmiento, J. L., and J. Toggweiler, 1984: A new model for the role of the oceans in determining atmospheric $P_{\mathrm{CO}_{2}}$. Nature, $\mathbf{3 0 8}$, 621-624, https://doi.org/10.1038/308621a0.

Smith, W. H., and D. T. Sandwell, 1997: Global sea floor topography from satellite altimetry and ship depth soundings. Science, 277, 1956-1962, https://doi.org/10.1126/ science.277.5334.1956.

St. Laurent, L. C., J. M. Toole, and R. W. Schmitt, 2001: Buoyancy forcing by turbulence above rough topography in the abyssal Brazil Basin. J. Phys. Oceanogr., 31, 3476-3495, https://doi.org/10.1175/1520-0485(2001)031<3476:BFBTAR> 2.0.CO;2.

Stommel, H., and A. Arons, 1959: On the abyssal circulation of the world ocean-I. Stationary planetary flow patterns on a sphere. Deep-Sea Res., 6, 140-154, https://doi.org/10.1016/ 0146-6313(59)90065-6.

Stone, P. H., 1966: On non-geostrophic baroclinic stability. J. Atmos. Sci., 23, 390-400, https://doi.org/10.1175/1520-0469(1966) $023<0390$ :ONGBS $>2.0$.CO; 2 .

Talley, L. D., 2013: Closure of the global overturning circulation through the Indian, Pacific, and Southern Oceans: Schematics and transports. Oceanography, 26 (1), 80-97, https://doi.org/ 10.5670/oceanog.2013.07.

Thompson, L., and G. C. Johnson, 1996: Abyssal currents generated by diffusion and geothermal heating over rises.
Deep-Sea Res. I, 43, 193-211, https://doi.org/10.1016/ 0967-0637(96)00095-7.

Thorpe, S., 1987: Current and temperature variability on the continental slope. Philos. Trans. Roy. Soc. London, 323A, 471-517, https://doi.org/10.1098/rsta.1987.0100.

Thurnherr, A., and K. Speer, 2003: Boundary mixing and topographic blocking on the Mid-Atlantic Ridge in the South Atlantic. J. Phys. Oceanogr., 33, 848-862, https://doi.org/ 10.1175/1520-0485(2003)33<848:BMATBO > 2.0.CO;2.

_ L. Lt. Laurent, K. Speer, J. Toole, and J. Ledwell, 2005: Mixing associated with sills in a canyon on the midocean ridge flank. J. Phys. Oceanogr., 35, 1370-1381, https://doi.org/10.1175/ JPO2773.1.

Toole, J. M., 2007: Temporal characteristics of abyssal finescale motions above rough bathymetry. J. Phys. Oceanogr., 37, 409-427, https://doi.org/10.1175/JPO2988.1.

Walin, G., 1982: On the relation between sea-surface heat flow and thermal circulation in the ocean. Tellus, 34, 187-195, https:// doi.org/10.3402/tellusa.v34i2.10801.

Waterhouse, A. F., and Coauthors, 2014: Global patterns of diapycnal mixing from measurements of the turbulent dissipation rate. J. Phys. Oceanogr., 44 1854-1872, https://doi.org/10.1175/ JPO-D-13-0104.1.

Wenegrat, J. O., J. Callies, and L. N. Thomas, 2018: Submesoscale baroclinic instability in the bottom boundary layer. J. Phys. Oceanogr., 48, 2571-2592, https://doi.org/10.1175/JPO-D17-0264.1.

Wunsch, C., 1970: On oceanic boundary mixing. Deep-Sea Res., 17, 293-301, https://doi.org/10.1016/0011-7471(70)90022-7. 